\title{
Seasonal evolution of granular and columnar sea ice pore microstructure and pore network connectivity
}

\section{Article}

Cite this article: Oggier M, Eicken H (2022). Seasonal evolution of granular and columnar sea ice pore microstructure and pore network connectivity. Journal of Glaciology 68(271), 833-848. https://doi.org/10.1017/jog.2022.1

Received: 18 January 2021

Revised: 13 January 2022

Accepted: 14 January 2022

First published online: 18 February 2022

Key words:

Frazil ice; ice core; ice crystal studies;

ice physics; sea ice

Author for correspondence:

Marc Oggier, E-mail: moggier@alaska.edu
Marc Oggier (D) and Hajo Eicken (D)

International Arctic Research Center, University of Alaska Fairbanks, PO Box 757320, 99775 Fairbanks, USA

\begin{abstract}
Sea-ice pore microstructure constrains ice transport properties, affecting fluid flow relevant to oil-in-ice transport and biogeochemical processes. Motivated by a lack of pore microstructural data, in particular for granular ice and across the seasonal cycle, throat size, tortuosity, connectivity, and other microstructural variables were derived from X-ray computed tomography for brine-filled pores in seasonal landfast ice off northern Alaska. Data were obtained for granular and columnar ice during the ice growth, transition, and melt season. While granular ice exhibits a more heterogeneous pore space than columnar ice, pore and throat size distributions are comparable. The greater tortuosity of pores in granular $\left(1.2<\tau_{\mathrm{g}}<1.7\right)$ compared to columnar ice $\left(1.0<\tau_{\mathrm{c}}<1.1\right)$ compounded with a less interconnected pore space translates into lower permeability for granular ice during the growth season for a given porosity. The microstructural data explain findings of granular ice hindering vertical oil-in-ice transport during ice growth and transition stage. With granular ice more frequent in the changing Arctic, data from studies such as this are needed to inform improved modeling of porosity-permeability relationships.
\end{abstract}

\section{Introduction}

Sea ice is an essential component of Earth's climate system and plays an important role in polar marine ecosystems (Thomas, 2017). Sea ice serves both as a habitat for a broad range of flora and fauna, from microorganisms to higher trophic levels (Horner and others, 1992; Bluhm and Gradinger, 2008; Gradinger and others, 2010), and as a platform that accumulates and transports dissolved and particulate matter sustaining biological activity (Meiners and Michel, 2017). The distinct sea-ice microstructure plays a critical role in the biogeochemical transformation and cycling (Vancoppenolle and others, 2013; Steiner and others, 2016). In particular, pore microstructure helps control nutrient supply to ice microalgal communities, contributing to steep gradients in ice algal biomass in the bottommost ice layers (Arrigo, 2014) and near the surface (Ackley and Sullivan, 1994). However, the linkages between pore microstructure seasonal evolution and fluxes of nutrients, gases and dissolved organic matter are still poorly understood. Lack of relevant pore microstructural data for the two most common ice textural classes, granular and columnar ice, to help improve permeability-porosity modeling are a particular limitation (Steiner and others, 2016; Steffen and others, 2018).

Such pore microstructural data are also relevant in the context of contaminant entrainment and transport in sea ice, specifically the percolation of oil. In recent years, growing maritime and resource development activities in the Arctic (Eguíluz and others, 2016), have increased the probability for oil spills in ice-covered waters (Wilkinson and others, 2015). Potential harmful impacts on Arctic ecosystems have placed an emphasis on improved spill response in the Arctic (Arctic Council, 2013). Understanding the movement of crude oil within sea ice is crucial to improved spill response capabilities and to effective clean-up efforts. Recent work by Oggier and others (2020b) highlights the need for pore microstructural data, in particular pore network connectivity, to support the prediction of oil movement in sea ice. Furthermore, an empirical 5 -stage oil migration model drawing on large-scale ice tank experiments (Oggier and others, $2020 b$ ) also emphasized the need for data on the seasonal evolution of pore microstructure. Measurements for granular ice are lacking in particular. As shown by Oggier and others (2020b), granular ice, typically present in the surface ice layers, greatly hinders upward migration and surfacing of crude oil following an under-ice oil release.

Owing to its common occurrence in the upper ice layers, derived from a consolidation of frazil ice during the early ice-growth stages, granular ice and its microstructure play an important role in a number of contexts, such as flooding of sea ice and snow-ice formation (Webster and others, 2018) or microwave remote sensing of the ice cover (Lubin and Massom, 2006). Given the lack of microstructural data in particular for granular ice, this study aims to quantify its pore microstructure relative to that of columnar ice, with a focus on pore-space networks and related metrics previously identified as constraining movement of fluids and gases through sea ice, such as throat size, connectivity and tortuosity. These microstructural parameters are relevant as well for our understanding of the nutrient cycle and biogeochemical processes. Drawing on core sampling and ice property characterization of first-year landfast ice in northern Alaska, we explore the seasonal evolution of sea-ice pore microstructure derived from 


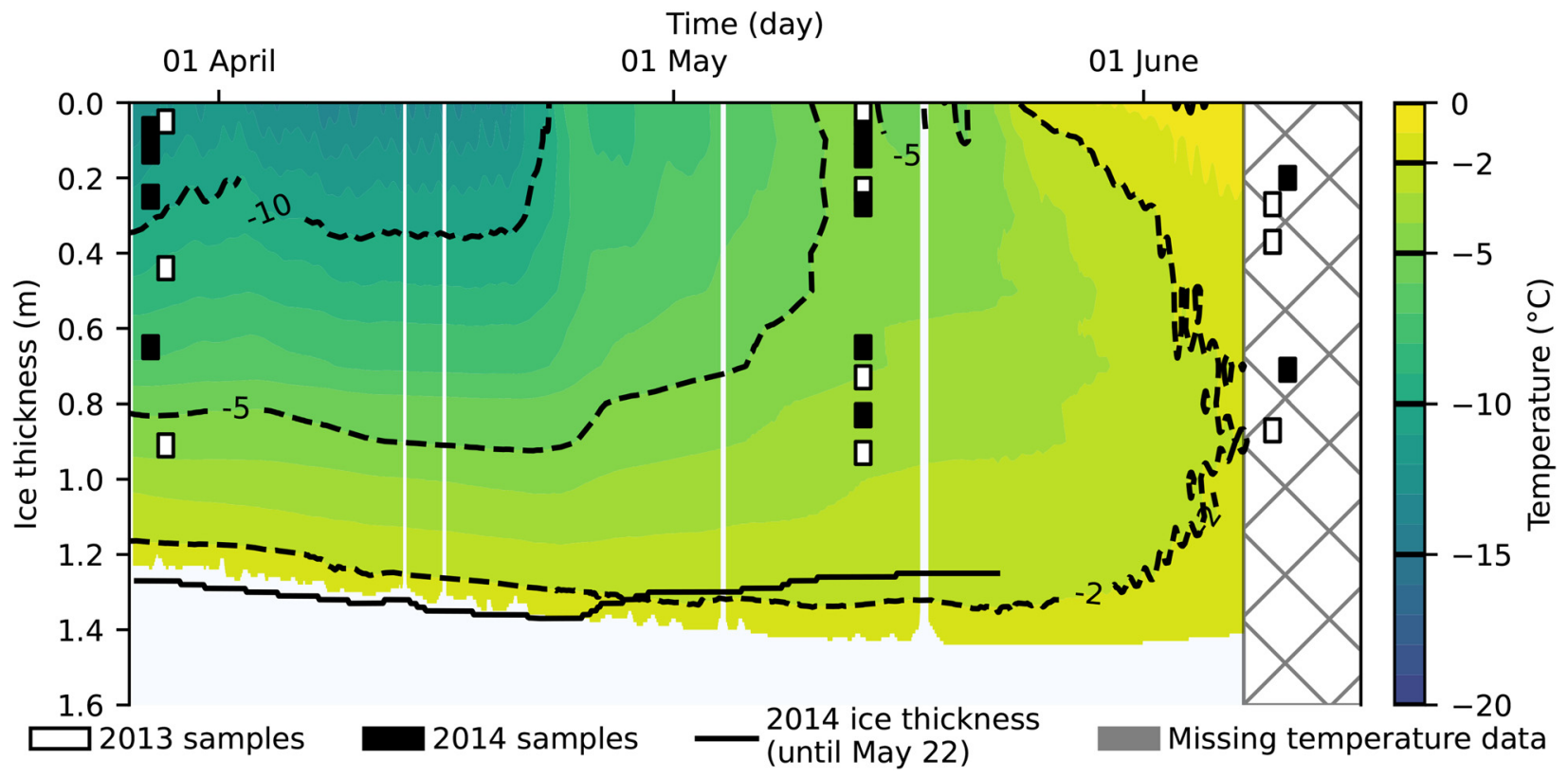

Fig. 1. Location and timing of collection of samples used for X-ray tomography. Background represents the ice temperature field measured by thermistor strings at the Utqiagivik ice mass balance station in 2014. The ice bottom is obtained by acoustic measurement (Eicken, 2016).

computed tomography $(\mathrm{CT}) \mathrm{X}$-ray images. In addition to deriving ice microstructural features of broader interest, we quantify variables such as pore connectivity and tortuosity that are central to transport process modeling and support the development of an oil-in-ice percolation model.

\section{Background}

Sea-ice pore space microstructure and pore network connectivity impact many of the physical and biogeochemical processes within the ice cover (Hudier and others, 1995; Eicken and others, 2002; Vancoppenolle and others, 2007; Arrigo, 2017). The size, shape, and spatial arrangement of the brine-filled pore space evolves with temperature changes (Petrich and Eicken, 2017). Cooling of the ice is associated with freezing of brine, potential salt precipitation and segregation of pores. In contrast, warming, whether during winter storm events or in spring toward the end of the icegrowth season, enlarges brine inclusions, increasing connectivity of the pore space (Pringle and others, 2009). In spring, when the ice becomes permeable, meltwater percolates through the pore space, desalinating the ice cover, but also carrying particulate material and nutrients (Freitag, 1999; Krembs and others, 2011). The physical properties of the ice are tightly linked with nutrient and light availability for microbial communities that colonize the ice bottom layers, where environmental conditions are more stable and pore connectivity constrains nutrient supply (Arrigo, 2017). The pore space morphology also provides microorganisms with protection from larger predators (Krembs and others, 2011).

As sea water cools below its freezing point, small ice crystals form in the upper layers of the ocean. The consolidation of such frazil ice once it has floated to the surface, yields ice of granular texture with small, isometric, randomly oriented grains with small intergranular brine inclusions. Underneath such an ice cover composed of granular ice, quiescent conditions typically foster the growth of sea ice through accretion, leading to vertically elongated ice crystals known as columnar ice (Petrich and Eicken, 2017). The convective overturning of brine in the ice and associated drainage processes result in the formation of brine channels which extend vertically over several $\mathrm{cm}$ to $\mathrm{dm}$, with feeder channels extending at $45^{\circ}$ (Cole and Shapiro, 1998; Wells and others, 2011).
The pore microstructure of both columnar and granular ice has been described qualitatively by Weissenberger and others (1992) and quantitatively by Perovich and Gow (1991), Bock and Eicken (2005), and Crabeck and others (2016). Most of the Arctic ice cover is composed of columnar ice (Weeks, 1998). The seasonal evolution of its pore microstructure is reasonably well understood (Cole and Shapiro, 1998; Cottier and others, 1999; Light and others, 2003) and different models relating aspects of pore microstructure to ice macroscopic properties have been developed (Petrich and others, 2006; Golden and others, 2007; Jones and others, 2012; Steffen and others, 2018). Brine movement through columnar ice has been quantified in the context of percolation transitions in a pore network (Pringle and others, 2009; Steffen and others, 2018) or mushy-layer theory (Feltham and others, 2006; Griewank and Notz, 2013). In contrast, granular ice pore microstructure has received much less attention. Despite the substantial contrasts in microstructure described as tortuous (Weissenberger and others, 1992; Lieblappen and others, 2018) relative to columnar ice, quantitative data are lacking. The few existing measurements of permeability and resistivity (Freitag, 1999; Freitag and Eicken, 2003; Kawamura and others, 2006; O'Sadnick and others, 2016) are not sufficient to inform the development of fluid flow through granular ice. Hence, the presence of granular ice is often either not considered (Golden and others, 2007; Griewank and Notz, 2013) or aggregated with columnar ice in representations of ice stratigraphy (Buffo and others, 2018).

\section{Methods}

\section{Sample collection}

We collected sea-ice samples for microstructure analysis in spatially homogeneous, level undeformed landfast ice at Utqiagvik, Alaska, during the winters and springs of 2013 and 2014 (Fig. 1). The ice is representative of Arctic undeformed sea ice, both in terms of microstructure and ice properties (Druckenmiller and others, 2009; Oggier and others, 2020a). We collected microstructure samples at three different times throughout the seasonal cycle to be representative of the growth period (end of March), the transition to the melt season 
(mid-May), and the melt period (mid-June). Figure 1 shows the sea ice temperature from April to June 2014. Winter 2014 was warmer than 2013 by about $2^{\circ} \mathrm{C}$ on average (Eicken, 2016). At the same time, we measured temperature and salinity profiles on co-located ice cores, using standard methods (Oggier and others, 2020a). Brine volume fraction was later computed from salinity and temperature profiles (Cox and Weeks, 1983).

Samples for X-ray tomography were centrifuged in a refrigerated centrifuge at in situ temperature for $5 \mathrm{~min}$ at $1500 \mathrm{rpm}$ immediately after collection, sealed in aluminum foil and polyethylene, and then stored at $-40^{\circ} \mathrm{C}$ for further processing. Based on thin section analysis performed by O'Sadnick (2015) on an ice core extracted contemporaneously at the same location, we selected samples from the upper ice cover $(0-20 \mathrm{~cm})$ of granular texture and samples from the interior $(30-100 \mathrm{~cm})$ of columnar texture. A few samples collected between 20 and $30 \mathrm{~cm}$ consisting predominantly but not exclusively of granular ice were grouped with the granular samples. The first letter of the sample names refers to the ice texture (Granular or Columnar), while the second letter indicates the seasonal stage (Growth, Transition or Melt). The letters are followed by an incremental number. An asterisk denotes samples without vertical connection, defined as the presence of a connected pore space extending from the bottom to the top of the sample. For example, GM- $0^{*}$ refers to a sample of granular ice collected during the melt period without vertical connection.

\section{$X$-ray computed tomography imaging}

Each sample was lathed into a cylinder of $30 \mathrm{~mm}$ diameter and 30 $\mathrm{mm}$ height in a cold room at ambient temperatures of -15 to $-20^{\circ} \mathrm{C}$. For the CT-imaging, a Skyscan 1074 portable micro-CT was installed in a temperature-controlled sub-chamber of the cold room set at $-20^{\circ} \mathrm{C}$. During the imaging process, samples were set on a rotating stage and rotated $180^{\circ} \sim$ the vertical axis by increments of $0.9^{\circ}$. At each step, an X-ray projection was captured on the instrument's $768 \times 576$ pixel 8 -bit camera with a pixel size of $41.5 \times 41.5 \mu \mathrm{m}$. The $\mathrm{X}$-ray source was set to a voltage of $40 \mathrm{keV}$ and a current of $1 \mathrm{~mA}$ with an exposure time of about $540 \mathrm{~ms}$ (O'Sadnick and others, 2016). We used the NRecon software (Bruker microCT, Kontich, Belgium) to reconstruct the $3 \mathrm{D}$ CT volume. Each volume consists of a large number of discrete cubic elements, known as voxels.

During the reconstruction process, each voxel was given a Hounsfield value, measured in Hounsfield Units (HU), which corresponds to its average linear X-ray attenuation coefficient $\mu$, a function of the atomic number and the radiation energy (Hounsfield, 1973):

$$
H U=1000 \cdot\left(\frac{\mu-\mu_{w}}{\mu_{w}-\mu_{a}}\right)
$$

where $\mu_{\mathrm{w}}$ and $\mu_{\mathrm{a}}$, are the linear absorption coefficients of water and air and, by definition, have Hounsfield values of $\mathrm{HU}_{\mathrm{a}}=-1000 \mathrm{HU}$, and $\mathrm{HU}_{\mathrm{w}}=0 \mathrm{HU}$, respectively. Crabeck and others (2016) and Kawamura (1988) find Hounsfield values of $-74 \mathrm{HU}$ and $-83 \mathrm{HU}$ for ice, respectively. Hounsfield values for brine of increasing salinity and precipitated salts vary from 60 $\mathrm{HU}$ up to $700 \mathrm{HU}$. Since a voxel may contain different phases, its Hounsfield value depends on the volume fraction of air $\left(V_{\mathrm{a}}\right)$, ice $\left(V_{\mathrm{i}}\right)$, or brine $\left(V_{\mathrm{b}}\right)$, with the Hounsfield value of the brine, $\mathrm{HU}_{\mathrm{b}}$, given as:

$$
H U=V_{a} H U_{a}+V_{i} H U_{i}+V_{b} H U_{b}
$$

$$
1=V_{a}+V_{i}+V_{b}
$$

To simplify the calculation, we used a Hounsfield value for brine of $200 \mathrm{HU}$. We set the range of $\mathrm{HU}$ from -1000 to $638 \mathrm{HU}$, which encompasses air, ice, and brine, and neglects any artifacts present at higher values and subsequently converted to values between 0 and 255. The 3D CT volumes were exported into vertical stacks of 8-bit images. Each image represents a horizontal slice of the original ice sample (see Supplemental material).

\section{Microstructure analysis}

\section{Post-processing}

Each sample was examined individually. For samples with columnar ice texture, we determined the preferential orientation of the sub-parallel brine layers and rotated the sample along its vertical axis so that brine layers were parallel to the horizontal $\mathrm{x}$-axis. This realignment also facilitates visual intercomparison between samples. Crystals in granular ice are randomly oriented (Petrich and Eicken, 2017), so this step was skipped for granular samples.

As the surface of the cylindrical ice samples presented defects due to machining, we selected a region of interest centered in the sample that omitted the outer layer of the sample cylinder. We extracted a cuboid with a square base of 375 pixels $(15 \mathrm{~mm})$ edge length in the $x-y$ plane, and 450 pixels $(18 \mathrm{~mm})$ in the vertical (z) direction. We applied a 3D 3-pixel median filter on the selected volume to reduce noise.

To segment the images, we used a threshold based on a mixture model approach (Eqn. 2). Thus, every pixel with less than $50 \%$ ice was categorized either as air or brine. During the centrifugation process, most of the brine was extracted from the samples. For highly connected samples, almost no brine remained in the samples. In this case, we assumed $V_{\mathrm{b}}=0$, leading to an airice threshold $\mathrm{Hu}_{\mathrm{ai}}$ of $-540 \mathrm{HU}$. Lower values correspond to voxels with more than $50 \%$ air (Table 1). Otherwise, some of the brine remained trapped in pores disconnected from the sample surface. As the connectivity of sea ice decreases with decreasing temperature (Pringle and others, 2009), a larger fraction of brine remained in colder samples. Under the assumption that the fraction of ice is $50 \%$, replacing a small fraction of air by brine, e.g. $V_{\mathrm{fb}}=0.05$, respectively, $V_{\mathrm{fb}}=0.1$, increases the air-ice threshold value to $-480 \mathrm{HU}$, respectively to $-420 \mathrm{HU}$. To account for the time of year the sample was collected and the temperature of the sample, we selected 3 different air-ice thresholds (Table 1). The ice-brine threshold was set at $50 \%$ ice and $50 \%$ brine, leading to $\mathrm{HU}_{\mathrm{ib}}=60$ HU. The final threshold value for each sample was based on a combination of the seasonal stage, ice temperature, and bulk salinity. We used the threshold values converted to the closest grayvalue number to segment each CT volume into ternary images. One of the main drawbacks of micro-CT imagery of centrifuged samples is the technical impossibility to distinguish between air bubbles and empty brine pockets, as both are filled with air after centrifugation. Thus, we finally merged the air and brine phases together to obtain binary images.

\section{Pore network extraction and microstructure analysis}

In addition to the total and open pore space, we defined the following two subsets of the open pore space:

1. Vertically connected pore space: connected to both the bottom and the top face of the sample, allowing for fluid movement from the bottom to the top across the sample.

2. Bottom connected pore space: connected to the bottom of the sample, including pores that terminate inside the sample volume. 
Table 1. Estimation of $\mathrm{HU}_{\mathrm{ai}}$ from mixture model as a function of sample temperature and period of collection

\begin{tabular}{lcccc}
\hline Period, ice temperature & $V_{\mathrm{a}}$ & $V_{\mathrm{b}}$ & $\mathrm{V}_{\mathrm{i}}$ & $\mathrm{HU}_{\mathrm{ai}}$ \\
\hline Melt, warm, or growth, warm & 0.50 & 0.00 & 0.5 & $\mathbf{- 5 4 6}$ \\
Melt, cold or growth, warm & 0.60 & 0.00 & 0.4 & $\mathbf{- 6 3 2}$ \\
& 0.45 & 0.05 & 0.5 & $\mathbf{- 4 7 5}$ \\
Growth, cold & 0.55 & 0.05 & 0.4 & $\mathbf{- 5 8 0}$ \\
& 0.40 & 0.10 & 0.5 & $\mathbf{- 4 2 0}$ \\
& 0.45 & 0.15 & 0.4 & $\mathbf{- 4 5 2}$ \\
\hline
\end{tabular}

Final HU threshold is bold. $V_{\mathrm{a}}, V_{\mathrm{b}}$, and $V_{\mathrm{i}}$ are volume fractions of air, brine, or ice in the voxel.

Further data analysis was carried out using Python 3.8 (Van Rossum and Drake, 2009) with packages that included mainly NumPy (van der Walt and others, 2011), Pandas (McKinney, 2010), Matplotlib (Hunter, 2007), and SciPy (Virtanen and others, 2020). For each pore space subset, we computed the pore volume fraction as the ratio between the number of voxels belonging to a particular pore space subset and the total number of voxels in the sample.

We used the open-source python module Porespy v. 1.2.0 (Gostick and others, 2019) to extract a representation of the pore and throat network from a selected pore space, using the SNOW algorithm (subnetwork of the over-segmented watershed). The SNOW algorithm initially segments the pore space using the watershed algorithm developed for sedimentary rocks, which divides the pore space according to the measured local thickness (Rabbani and others, 2014). The segmentation yields a pore space divided into regions characterized by the maximal local thickness, which appears as a peak in the watershed representation of the pore space. The algorithm addresses potential over-segmentation of the pore space in nongranular media is in two steps. First, thin extensions connecting large pores are merged with one of the neighboring pores according to a reanalysis of the local geometry. Second, large adjacent pore regions are merged when their respective peaks were closer to each other than to the nearest voxels of the adjacent ice grains (Gostick, 2017). Each final region corresponds to a pore, and throats are defined as connections between two pores. The size of the pore is defined as the radius of the largest sphere inscribed in the region, without exceeding the boundaries of the pore. The throat length corresponds to the center-to-center distance between two pores, less the radius of each pore. The throat radius was then given by the radius of the inscribed sphere at the cross-section between the two pores. The distribution of the pore size, throat size and length can be computed from the network geometry. In this paper, we used the term pathway to refer to a succession of connected nodes (pores) and sticks (throats). While the SNOW algorithm performs well on sedimentary rocks, the use of the watershed algorithm has been applied successfully to other types of porous media ranging from granular to fibrous (Jervis and others, 2018; Banerjee and others, 2019). We used the OpenPNM v. 2.5.1 module (Gostick and others, 2016) in conjunction with ParaView (Ahrens and others, 2005) to visualize the pore space. Each node corresponds to an identified sphere, and a stick to a throat.

Using a PoreSpy subroutine we searched for any pathways connecting pores present on the bottom face and the pores present on the top face. The fractional connectivity $f_{c}$ within the sample is given by:

$$
f_{c}=\frac{N p s e}{N p s}
$$

Where $N_{\mathrm{ps}}$ is the total number of pores present on the start face of the volume, and $N_{\text {pse }}$ is the number of pores present on the start face of the volume and connected via a path to the opposite end face (Pringle and others, 2009). By definition, the fractional connectivity is independent of the number of paths and their shape. We computed the fractional connectivity using a cuboid with a horizontal extent of $400 \times 400$ pixels and increasing height from the surface up to the full sample height (2-375 slices). According to Pringle and others (2009) an exponential curve of the form $f=A \exp \left(-z / z_{0}\right)$ can be fitted to the data. The value $z_{0}$ corresponds to the vertical correlation length of the sample, where $A$ is a constant. The specific surface area (SSA), $A_{s}$, is defined as the ratio between the surface of the pore space and the volume of the pore space. It was measured using a PoreSpy subroutine, which fits a triangular mesh to smooth the cubic voxels that comprise the discretized pore space. This method leads to a lower SSA than the approach of Lieb-Lappen and others (2017) who computed microstructural measures directly from the voxels.

In addition, we measured the tortuosity of the pore space. Several definitions exist for this metric describing the complexity of a pathway (Clennell, 1997). In fluid dynamics, the hydraulic tortuosity, $\tau_{\mathrm{h}}$, is used and defined as the ratio of the length along the flow path divided by the distance measured in a straight line in the direction of flow. However, the actual length of the flow path is difficult to measure without complex flow simulations. In this study, we use the geometric tortuosity defined by Gommes and others (2009) as the ratio between the geodesic distance, $L_{\mathrm{G}}$, and Euclidian distance, $L_{\mathrm{E}}$, between two points:

$$
\tau=\frac{L_{G}}{L_{E}}
$$

The Euclidian distance is the straight-line distance between those points, while the geodesic distance is the distance along the shortest path between two points fully contained within the pore space. The tortuosity tends to 1 as the pathway becomes more direct across the volume.

This method has been implemented in the python module FibTortuosity (Taillon and others, 2018), which does not require a significant computation effort. After adapting the module to our use, we repeatedly computed the tortuosity value over a cuboid with a horizontal extent of $400 \times 400$ pixels, and a vertical extent of 20 slices $\left(L_{\mathrm{E}}=0.8 \mathrm{~mm}\right)$. We repeated the measurement for subsamples of increasing vertical length under consideration from 5 to 200 slices, $\left(L_{\mathrm{E}}=8 \mathrm{~mm}\right)$, with the start face located every 10 vertical slices from the bottom of the sample.

\section{Results}

\section{Overview of microstructural data}

Figure 2 shows pairs of $3 \mathrm{D}$ volumetric renderings of the pore space for granular and columnar ice at different times of the year, representative of the ice growth, transition, and melt periods. Striking differences exist between granular (Fig. 2, left) and columnar (Fig. 2, right) ice texture, in line with the observations of Weissenberger and others (1992). First, as expected, the pore space in columnar ice is elongated along the vertical $\mathrm{z}$-axis. In the horizontal direction, following the rotation of the volume around the $\mathrm{z}$-axis, the remnant brine layers of columnar ice are oriented roughly parallel to the $\mathrm{x}$-axis. In granular ice, we do not observe any preferential orientation in any direction, thus no rotation along the $\mathrm{z}$-axis was applied. Second, although most pores of columnar ice are disconnected pockets during the growth season, all samples but two (CG-0, CT-2) have at least one channel extending through the full vertical extent of the sample. In contrast and despite the apparent tightness of the pore network 

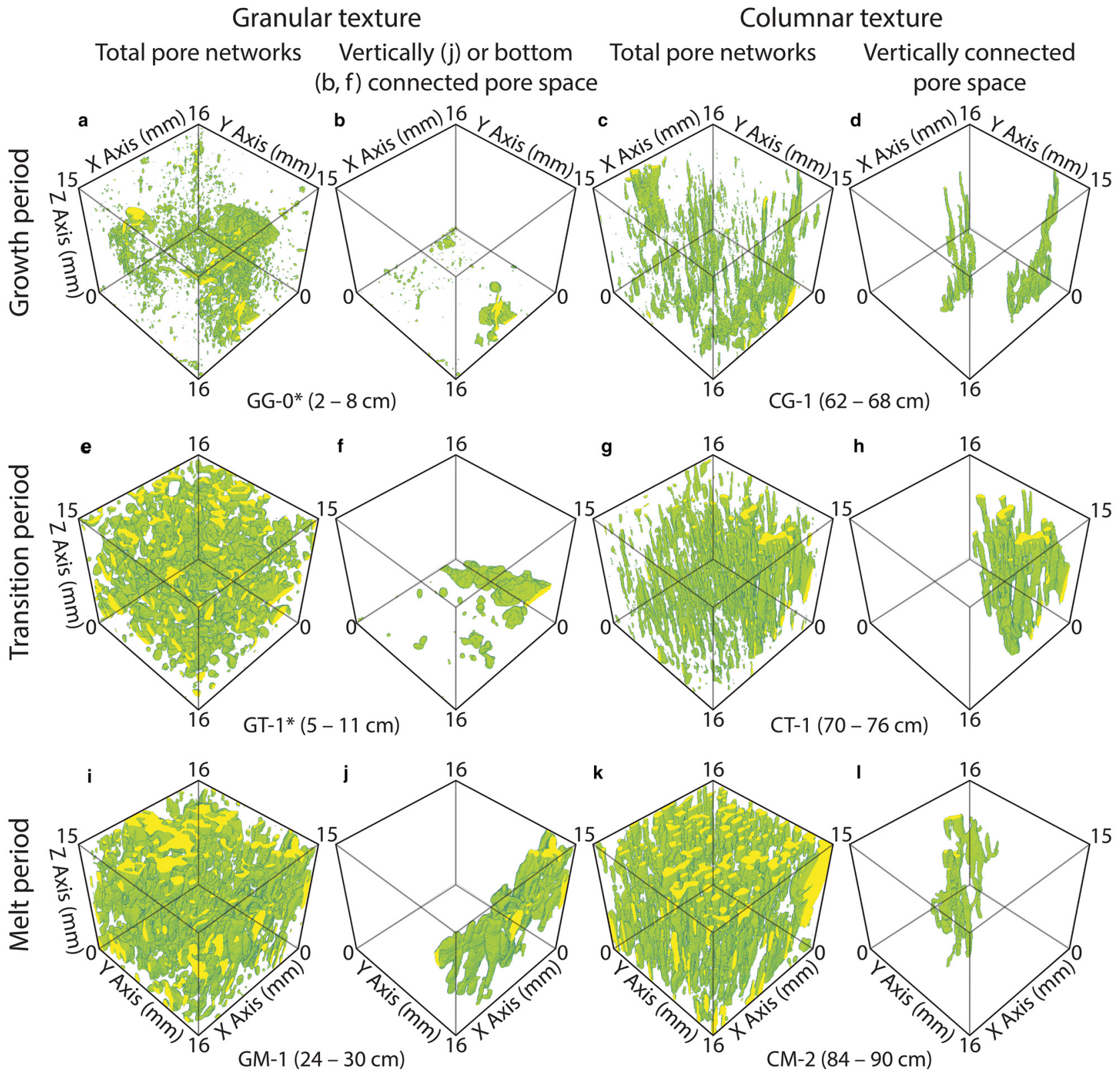

Fig. 2. Three-dimensional visualization of pore microstructure with respect to ice textural units (granular or columnar) and stage in the seasonal cycle of a cuboid measuring $16 \mathrm{~mm}$ along the horizontal edges and $15 \mathrm{~mm}$ height. For each sample, the full pore space is depicted on the left (a, c, e, g, j and I), and the vertically connected pore space on the right $(d, h, j, l)$. In absence of vertically connected pore space, the bottom connected pore space is shown for GG- $0^{\star}$ and $G G-1^{\star}(b, d)$.

in granular ice, the pore space in the granular samples remains often poorly connected at the sample length-scale with 9 out of 12 samples not vertically connected.

Third, at the pore scale, columnar ice pores are vertically elongated, with a horizontal cross-section significantly smaller than the vertical extent (Figs $2 c$, d). With the warming of the ice, the pores become larger but remain mostly long and straight (Fig. 2g), with few branches developing in the horizontal direction (Fig. 2h). In granular ice, the pores vary significantly in shape and size, but overall, the ratio between vertical to a horizontal extent is visibly smaller than for columnar ice (Fig. 2a). We notice the presence of a few macropores formed by large pores connected by small throats. With the warming of the ice, the pore network becomes more tortuous (Fig. 2e), with branching developing in all directions (Figs 2f, j).

Figure 3 shows an example of the extracted pore and throat network from the original pore space. Hereafter, we will use the term 'node' to refer to the pore of the extracted pore and throat network. At the pore scale, granular ice exhibits highly connected clusters of pores, with self-similarity indicative of fractal structure. As expected in columnar ice, the connections are mostly vertically oriented. We note that a vast majority of pores one would identify as brine tubes several $\mathrm{mm}$ long (Fig. $2 \mathrm{~h}$ ) are formed by a succession of poorly branched nodes and throats (Fig. 3b). Furthermore, we identify the presence of a few extreme cases where long tubes are made of a chain of nodes, connected exclusively to two throats, i.e. without branching (Fig. 3b).

Figure $4 \mathrm{a}$ shows the frequency of coordination numbers, $N_{\mathrm{c}}$, defined as the number of nodes directly linked by a throat to a given node. Nodes with a coordination number $N_{c}=1$ are of no interest from the perspective of connectivity. Obviously, $N_{\mathrm{c}}=0$ is a single, fully disconnected node. Despite being the most common $(f>65 \%)$, nodes with $N_{c}=1$ are either connected to a node of the same kind - forming a disconnected pair or terminating in an extension of a connected pore network. Analysis shows that nodes with a large coordination number $\left(N_{\mathrm{c}}>4\right)$ are often 


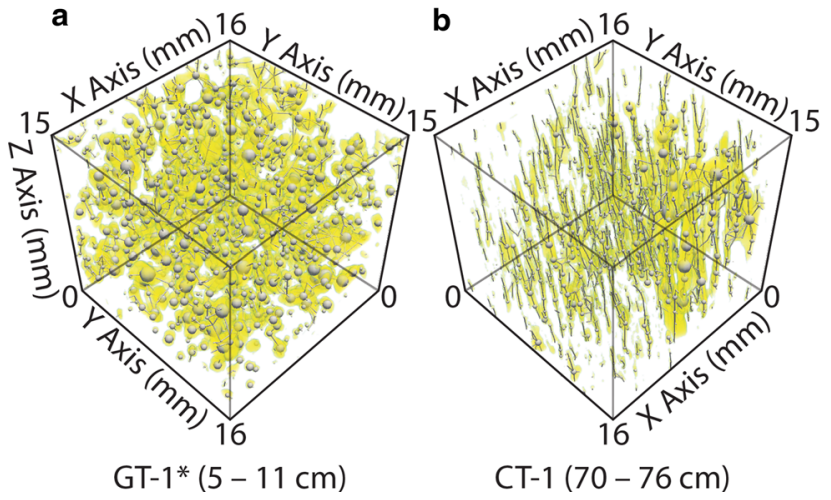

Fig. 3. Three-dimensional visualization of the extracted pore network for (a) GT-1* and (b) CT-1. The spheres represent nodes. The sticks represent throats. The corresponding pore space is shown as a light-yellow overlay.
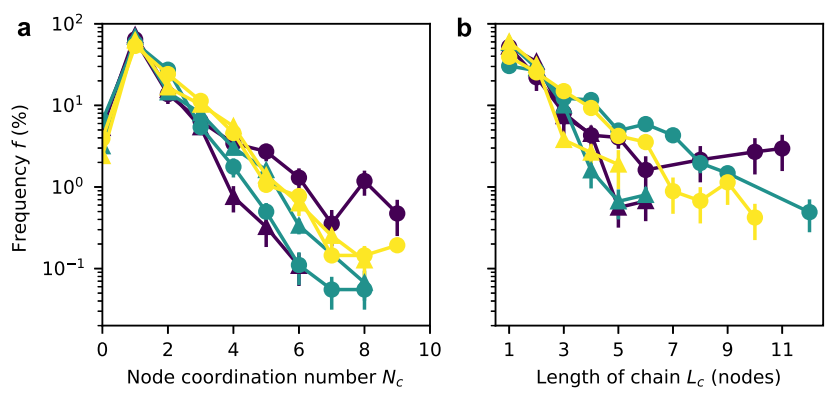

$\Delta$ Granular

O Columnar

Growth

Fig. 4. Pore network connectivity: (a) frequency of node coordination number Nc, and (b) node chain frequency of $L c$ consecutive nodes. A chain of nodes is defined as a set of consecutive nodes with one throat each linking two neighboring pores in the chain. By definition, all nodes of the chain have a coordination number of $N_{\mathrm{c}}=2$, excluding any branching. For (b) a logarithmic scale is used for the frequency.

found in larger pores, which in network representation can be constituted of multiple interconnected nodes. Nodes with a coordination number of $N_{\mathrm{c}}=2$ or $N_{\mathrm{c}}=3$ are often located either in a convoluted section of the pore space in granular ice, or in elongated pores of columnar ice. While columnar ice tends to have more nodes with a high coordination number than granular ice, their frequency remains overall small $(f<1 \%)$. The most noticeable difference is for $N_{c}>2$, which accounts for about $30 \%$ of the total node number in columnar ice, about twice as much as in granular ice.

Chains of connected nodes are of particular interest from the perspective of transport properties. A chain of connected nodes consists of a set of nodes each linked by a single throat to its two neighbors in the chain $\left(N_{c}=2\right)$. A chain is either terminated with an extremity $\left(N_{c}=1\right)$, or a branching $\left(N_{c}>2\right)$. Figure $4 \mathrm{~b}$ summarizes the frequency of chain length $L_{\mathfrak{c}}$, defined as the number of consecutive nodes with $N_{\mathrm{c}}=2$. Overall, small chains $\left(L_{\mathrm{c}}<3\right)$ are the most frequent in both ice textures. The longest chain observed in granular ice is about half of that of columnar ice, and accounts for less than $1 \%$ of the total pore number. For comparison, $10 \%$ of the chains in columnar ice are of similar length $\left(5 \leqslant L_{\mathrm{c}} \leqslant 7\right)$, and longer chains $\left(8 \leqslant L_{\mathrm{c}}\right)$ still account for several percent of the chain population. The frequency of those long chains in columnar ice are indications of numerous elongated pores, as illustrated in Fig. $3 \mathrm{~b}$.

Figure 5 shows the contribution of closed, vertically connected, and open porosity to the total porosity, along with the computed brine volume fraction from bulk salinity and temperature. The increase in porosity follows the rise in temperature, with the

total porosity increasing by a factor of four from the growth to the melt season. While closed porosity accounts for more than half of the total porosity during the growth season, its contribution decreases as the ice becomes more porous. At the same time, the contribution of open and vertically connected porosity increases with the advance in a seasonal stage. It is important to note that the two most porous samples (GT-2 and GM- $0^{*}$ ) are both composed of granular ice, and contribute to the visible decrease of the average value of vertically connected pore space from the transition to the melt season.

The computed brine volume fraction deviates significantly from the porosity inferred from the CT imagery for a number of samples considered individually. However, the average values for each seasonal stage are similar. In addition, computing Pearson's correlation coefficient between porosity and brine volume fraction by texture, we found that the correlation is significant for both granular ice $(R=0.62, p$-value $=0.050)$ and columnar $(R=0.89, p$-value $=0.001)$. Figure 5 shows that the difference between measured porosity and calculated brine volume fraction is much larger for granular ice than for columnar ice. In addition, porosity in columnar ice is always lower than the computed brine volume fraction.

\section{Pore and throat size distributions}

\section{Pore size distribution}

The cumulative distribution functions (CDF) of the pore diameter, throat diameter, throat length, and pore horizontal cross-section area are shown in Figure 6 for the total pore space (Figs $6 \mathrm{a}-\mathrm{h}$ ), and the subset of vertically connected pore space (Figs 6i-1). Overall, we observed an increase in pore and throat diameters and lengths with the advance in seasonal stage. The values of pore areas (Figs $6 \mathrm{~d}, \mathrm{~h}, \mathrm{l}$ ) are similar to data obtained by Perovich and Gow (1996, Fig. 7), and equivalent cross-sections estimated by Light and others (2003). With respect to the total pore space, the columnar ice is more homogeneous with a smaller spread of both pore and throat diameter, as well as throat length. During the transition and melt seasons, pore and throat diameters above $0.1 \mathrm{~mm}$ increase strongly in granular ice relative to columnar ice. Figures $6 \mathrm{i}-\mathrm{k}$ suggests that vertically connected pore space is made up of pores and throats with the largest diameters, but similar throat length. A table with key pore and throat size parameters is available as Supplementary material.

\section{Fractional connectivity}

Figure 7 a shows the decay in fractional connectivity as a function of the height of the sample. In columnar ice, we observe the same exponential decay as Pringle and others (2009) for low-porosity $(\varphi<8 \%)$. In percolation theory, the correlation length is equivalent to the average distance between two connected pores. The porosity value at which the correlation length diverges is known as the percolation threshold, above which the pore space is considered fully connected. The correlation length follows a similar power law of the form $f=\mathrm{kz}^{\alpha}$ for the same porosity range (Fig. $7 \mathrm{~b}, \varphi<8 \%$, dashed line). We expected an asymptotic behavior above the percolation threshold, here $\varphi_{c}=8 \%$. For granular ice, we were able to fit the fractional connectivity to an exponential curve. However, the wide spread of the correlation length and porosity prevented us from fitting a power law and estimating a percolation threshold for granular ice. Nonetheless, it is important to note that the correlation length of granular ice is overall much smaller than that of columnar ice, even for high porosity samples (Fig. 7b, dotted line). Only GT-0 shows a correlation length above $2 \mathrm{~mm}$ for granular ice. Our data do not indicate that either a linear, power-law or exponential function would serve better to fit better the granular ice fractional connectivity. 


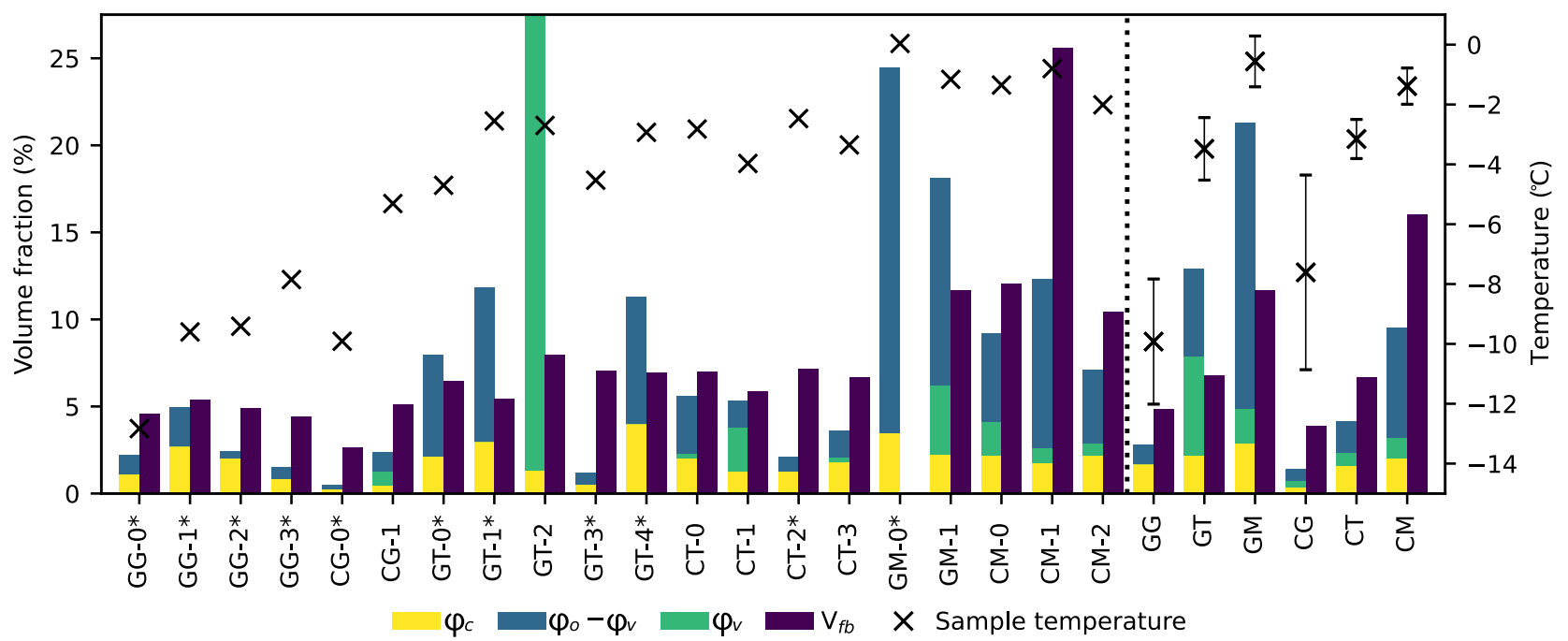

Fig. 5. Contribution of closed $\left(\varphi_{c}\right)$, vertically connected porosity $\left(\varphi_{v}\right)$ and open porosity $\left(\varphi_{0}-\varphi_{v}\right.$, i.e. not accounting for the vertically connected porosity), as measured on the imaged samples. The vertically connected porosity is a subset of the open porosity $\left(\varphi_{\mathrm{o}}\right)$. The brine volume fraction $\left(V_{\mathrm{fb}}\right)$ was computed from bulk salinity and temperature profile. The crosses $(X)$ indicate the temperature in the middle of the sample. The mean and Std dev. for samples as a function of the ice texture (Granular or Columnar) and period (Growth, Transition or Melt) and are displayed at right. Note that for each seasonal stage, we organized samples in order of increasing depth. The total porosity of $\mathrm{GT}-2 \varphi_{\mathrm{GT}-2}$ is $32 \%$.
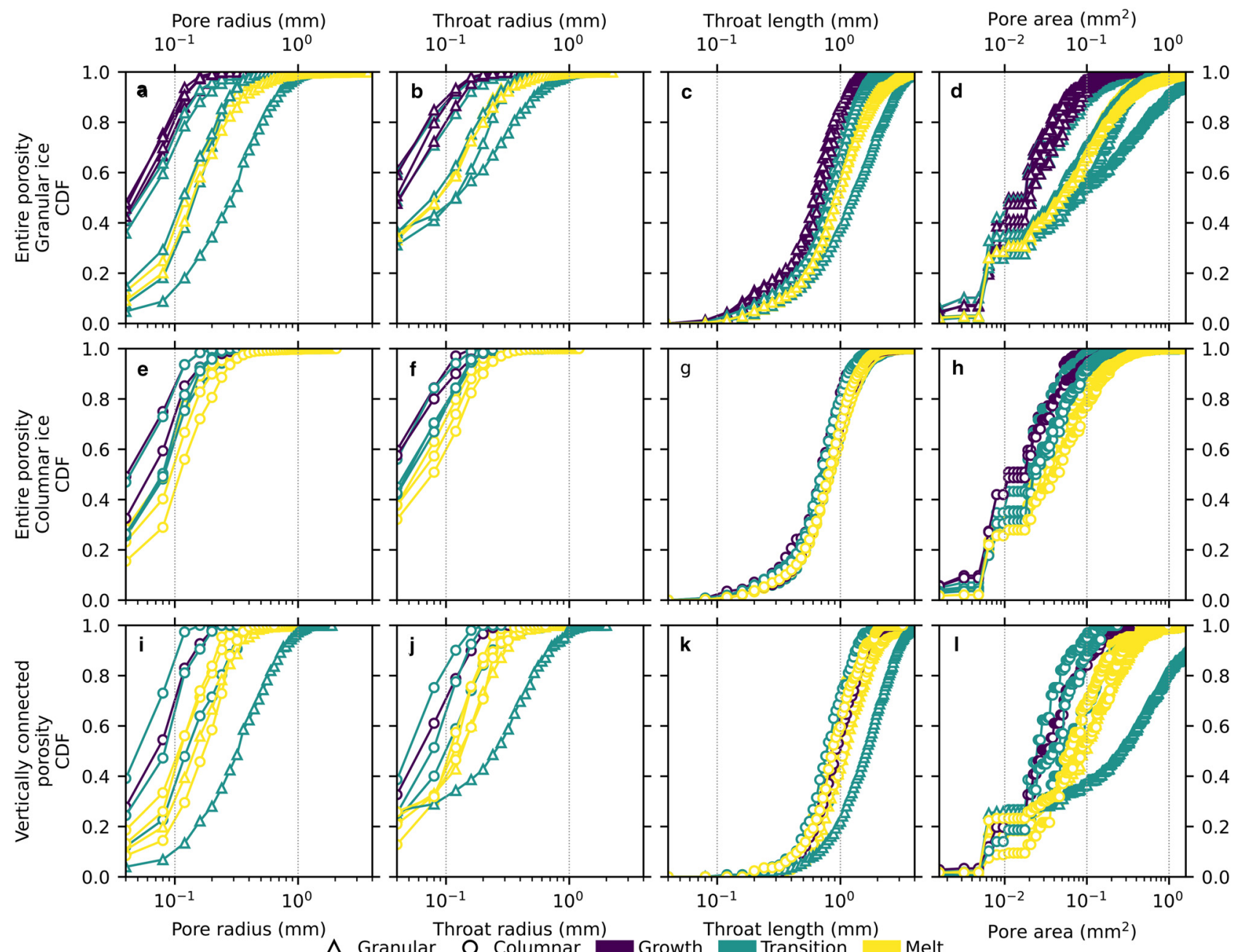

Fig. 6. Pore characteristics of granular and columnar ice as function of seasonal stages for the total pore network (a-h) and the vertically connected pore space (il): $(a, e, i)$ pore diameter, $(b, f, j)$ throat diameter, $(c, g, k)$ throat length and pore horizontal cross-sectional area $(d, h, l)$. 

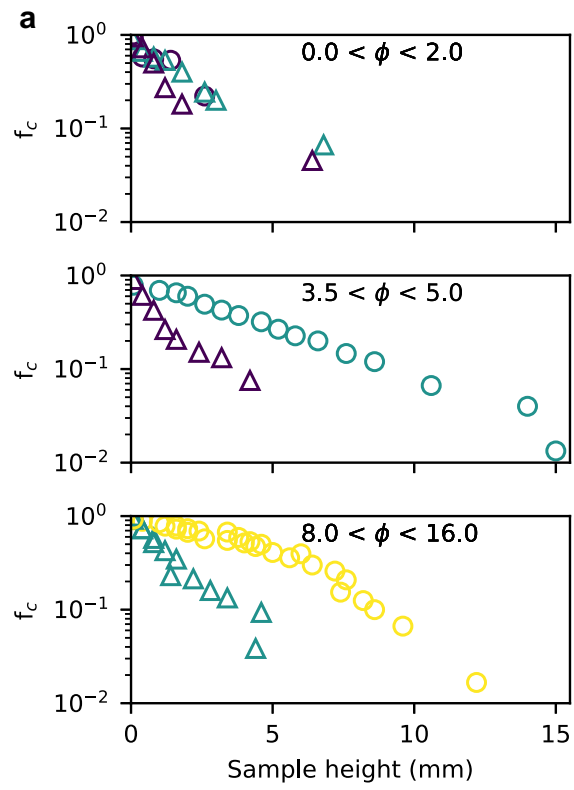

$\Delta$ granular
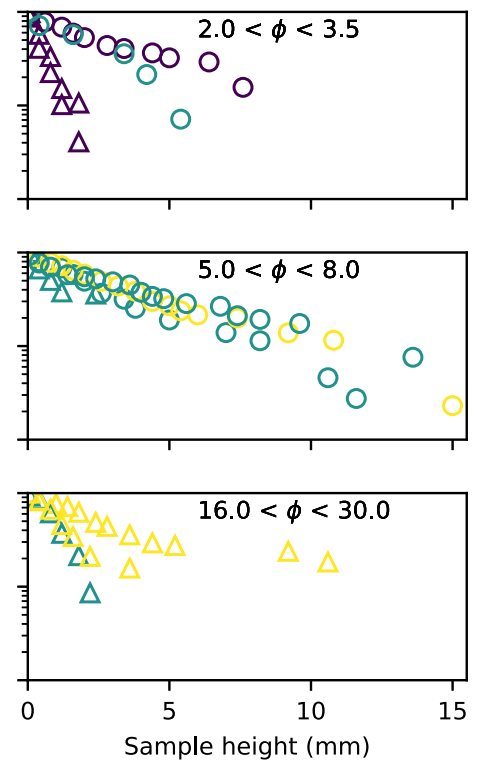

columnar

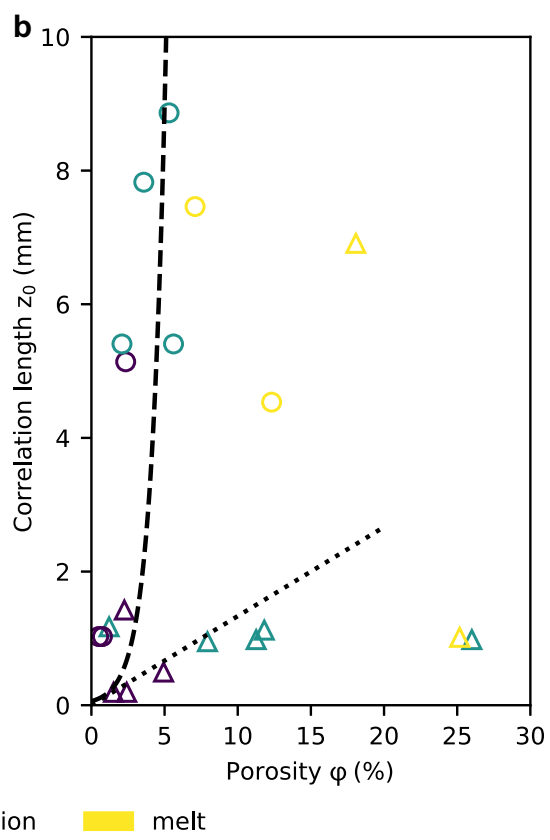

Fig. 7. Derivation of vertical correlation length $z_{0}$ for columnar and granular ice: (a) fractional connectivity $f_{\mathrm{c}}$ for different porosity ranges. (b) Vertical correlation length $z_{0}$. The dashed and dotted lines are a guide to the eye for columnar and granular ice.

\section{Tortuosity}

Figure 8a shows the distribution of the vertical tortuosity $\tau_{\mathrm{v}}$ as a function of crystal texture and seasonal stage computed for 0.8 $\mathrm{mm}$ high slices of the vertically connected pore space. The range of values is asymmetric, which is expected as tortuosity values range from 0 to infinity by definition. Overall, the tortuosity median and range are significantly smaller in columnar ice $\left(\tau_{\mathrm{v}, \mathrm{c}}=1.06\right)$ than in granular ice $\left(\tau_{\mathrm{v}, \mathrm{g}}=1.20\right)$. In addition, the difference tends to decrease with the advance in a seasonal stage. However, locally the tortuosity of granular ice can reach extreme values of up to $3.38,2.56$ or 1.48 depending on the seasonal stage. In contrast, the maximum value reached by columnar ice is 1.26 during the growth season.

For the vertically connected pore space, Figure $8 \mathrm{~b}$ shows the dependence of tortuosity on the vertical length under consideration. The differences in tortuosity for different seasonal stages and textures are striking: While changes in tortuosity within columnar ice are small (with a maximum of $+10 \%$ during the growth season), the tortuosity increases with the vertical length for granular ice. In addition, the interquartile range remains narrow in columnar ice, and increases greatly in granular ice. However, we note that tortuosity seems to reach a plateau at roughly $3 \mathrm{~mm}$ in granular ice, and $7 \mathrm{~mm}$ in columnar ice.

\section{Specific surface area}

Figure 9 summarizes the SSA of the connected pore space. The values are at the low end of the range measured by Lieb-Lappen and others (2017) for their samples' total porosity. The omission of closed pores, which tend to have a higher surface-to-volume ratio, shifts our distribution to a lower SSA. While the SSA distribution is the same for both ice textures $\left(\mathrm{SSA} \approx 13 \mathrm{~mm}^{-1}\right)$ during the growth season, the values for granular ice (SSA $\approx 6 \mathrm{~mm}^{-1}$ ) are about a third lower than those for columnar ice (SSA $\approx 9 \mathrm{~mm}^{-1}$ ) during the melt stage. During the transition stage, variability is large in the distribution for granular ice $\left(5 \mathrm{~mm}^{-1} \leqslant \mathrm{SSA} \leqslant 13 \mathrm{~mm}^{-1}\right)$, covering the whole range observed during the growth and melt stage. In contrast, the distribution in columnar ice during the transition stage remains similar to that of the growth stages $\left(10 \mathrm{~mm}^{-1} \leqslant \mathrm{SSA} \leqslant 14 \mathrm{~mm}^{-1}\right)$. Overall during the advance of the seasonal cycle, the SSA decreases for both ice textures.

\section{Discussion}

\section{Methodological advances and constraints}

Although many microstructure analyses rely on thin-section microphotography to describe pore size distribution (Perovich and Gow, 1991; Eicken and others, 2000; Light and others, 2003; Galley and others, 2015; Frantz and others, 2019), this destructive method is labor-intensive and mostly only allows for quantification of pore sizes every few millimeters (Frantz and others, 2019). The majority of studies drawing on 3D datasets that were derived from either magnetic resonance imaging (Eicken and others, 2000; Bock and Eicken, 2005; Galley and others, 2015) or CT scans (Lieblappen and others, 2018), limit their pore size analysis to slice-by-slice quantification. Thus, past studies - with few exceptions such as work by Pringle and others (2009) on columnar ice single-crystals, lacked information about the 3-D shape and connectivity of individual brine inclusions throughout the depth of a sample, preventing differentiation between pores and throats. By describing the pore space with a node-and-stick model, we are able to quantify not only the pore and throat size distribution, but also estimate the throat length distribution (Fig. 6).

Although one expects the throat radii to be much smaller than the pore radii, the measured throat radius distribution is barely smaller than the pore size distribution in sea ice, independent of the combination of ice textures and type of pore space (e.g. Figs $6 \mathrm{a}, \mathrm{b}, \mathrm{e}, \mathrm{f})$. Considering a single pathway, the radii of the spheres inscribed into the pore space that are identified as individual pores, are likely larger than the radii of the throats, identified as cylinders connecting two pores and fitting within the more confined portion of the pore space in between both pores. However, if we consider a pore space that is getting overall smaller, like a feeder of a brine channel, the pore radius of a feeder could be smaller than the throat radius of the main brine channel, even though they belong to the same pathway. Considering the total pore space, it is likely radii of pores corresponding to small, disconnected 

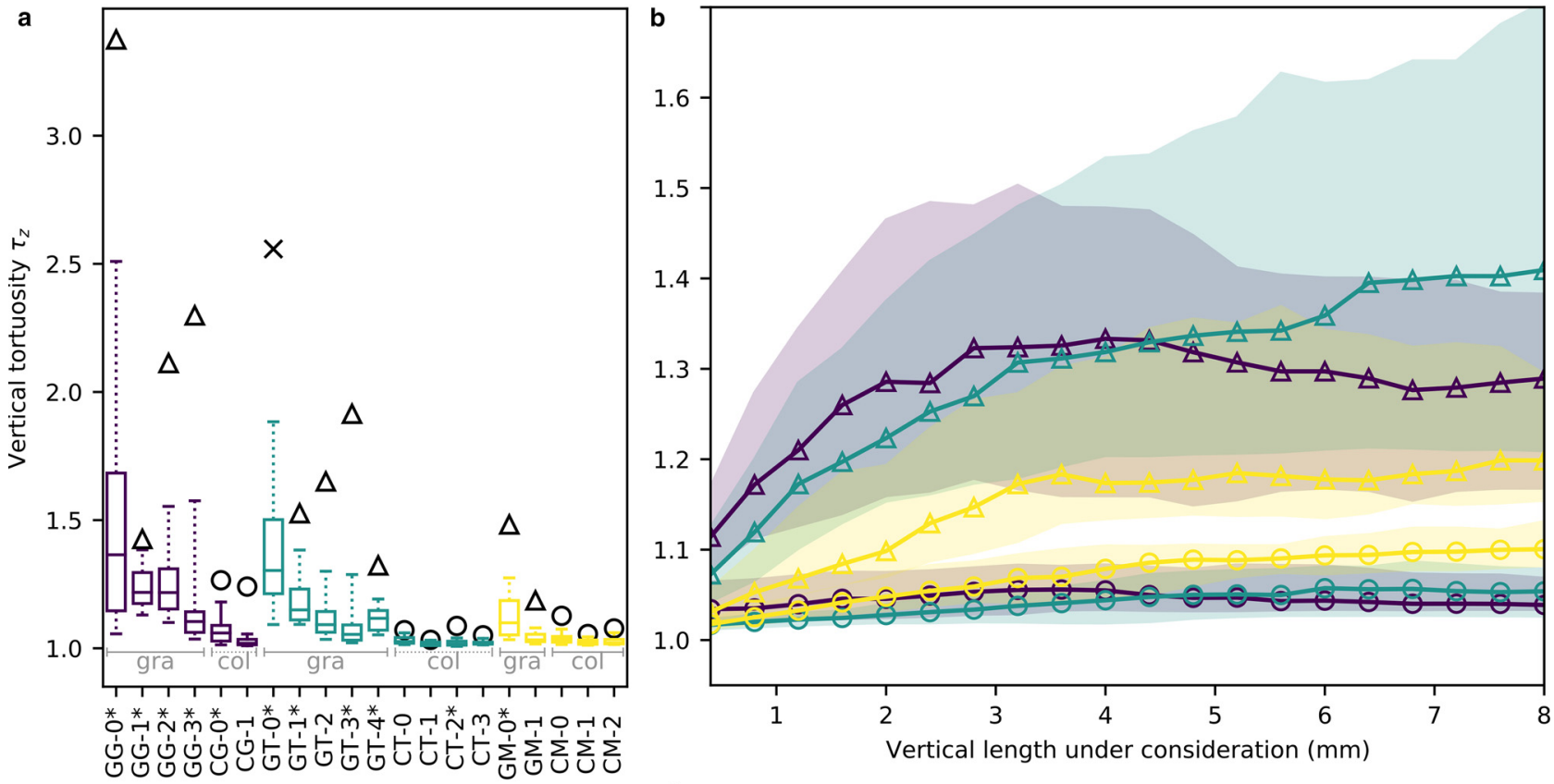

$\Delta$ granular $\mathrm{O}$ columnar growth transition melt

Fig. 8. Tortuosity along the vertical axis as a function of ice texture and seasonal stage: (a) Distribution of tortuosity computed for sample segments of $0.8 \mathrm{~mm}$ height. The boxplots show the median with the first and third quartiles. The whiskers are set at the 5th and 95th percentile. For clarity most outliers are omitted, but the maximum tortuosity is indicated by a black cross (x). Within each combination, samples are classified as a function of increasing depth. (b) Evolution of median tortuosity for all samples of each of the three growth/melt stages plotted against the vertical length under consideration. Shaded area includes data between the first and third quartiles.

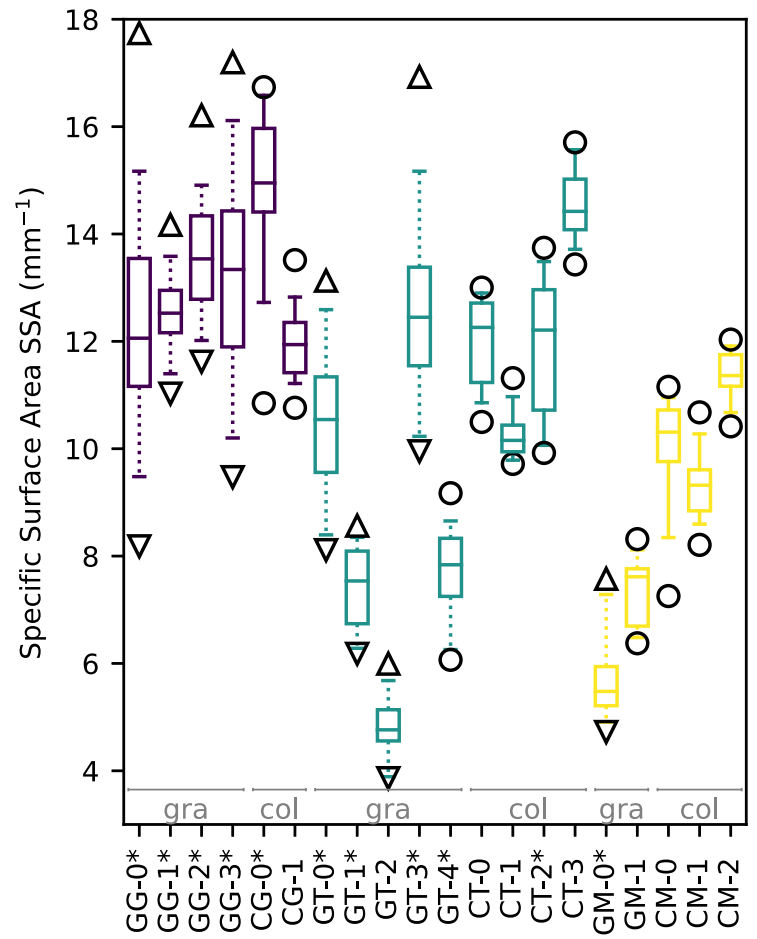

Fig. 9. Specific surface area (SSA) of the connected pore space computed for subsamples of $0.8 \mathrm{~mm}$ height. The boxplots show the median with the first and third quartiles. The whiskers are set at the 5th and 95th percentile. The upper and lower facing triangles indicate the maximum and minimum value for each sample, respectively. Triangles represent granular ice, and circles columnar ice.

pockets will be smaller than pore radii that are part of much larger brine inclusions. The pore and throat size distributions measured on a full sample are not necessarily significantly distinct from one another, which is in line with previous microstructural analysis finding pore sizes to conform to a lognormal or power-law distribution (Perovich and Gow, 1996; Bock and Eicken, 2005). At the same time, by explicitly segmenting the pore space into throats and pores, and through analysis of key variables describing these microstructural inventory elements (Fig. 6), this study illustrates that summary analysis of pore size distribution is not sufficient to gain insight into microstructural controls of transport properties.

The stick-and-node or throat-and-pore model was employed to extract connected pathways, as applied routinely in the analysis of granular sedimentary rocks such as sandstones (Silin and Patzek, 2006; Dong and Blunt, 2009), with grain microstructures somewhat comparable to granular ice. However, this method may have limitations in being applied to columnar ice pore space. While the SNOW algorithm successfully addressed oversegmentation of nongranular microstructure, resolving the elongated pore space of columnar ice, such as brine layers and brine tubes, remains a challenge. The algorithm was not designed to merge regions whose watershed peaks are farther away from one another than from the solid matrix. This leads to the creation of long chains of pores, especially in elongated pores (Fig. 4b), as well as highly connected nodes in narrow planar and tubular pores, both of which are more common in columnar ice than in granular ice. However, in applying the pore-and-throat model consistently for both ice types, the derived quantities and insights gained into microstructural contrasts and evolution can inform flow and transport modeling in sea ice, while highlighting some of the challenges to extract universally applicable measures of pore space microstructure.

The length of the major axis of the ellipsoid fitted to a brine inclusion is commonly used as a proxy for the pore size (Perovich and Gow, 1991; Eicken and others, 2000). Thus, the pore size distribution is likely to be shifted toward somewhat larger sizes, as it is inferred here from the radius of the largest spheres fitted within the pore space. This inscribed sphere radius would be smaller than the major axis of an ellipsoid inscribed into 


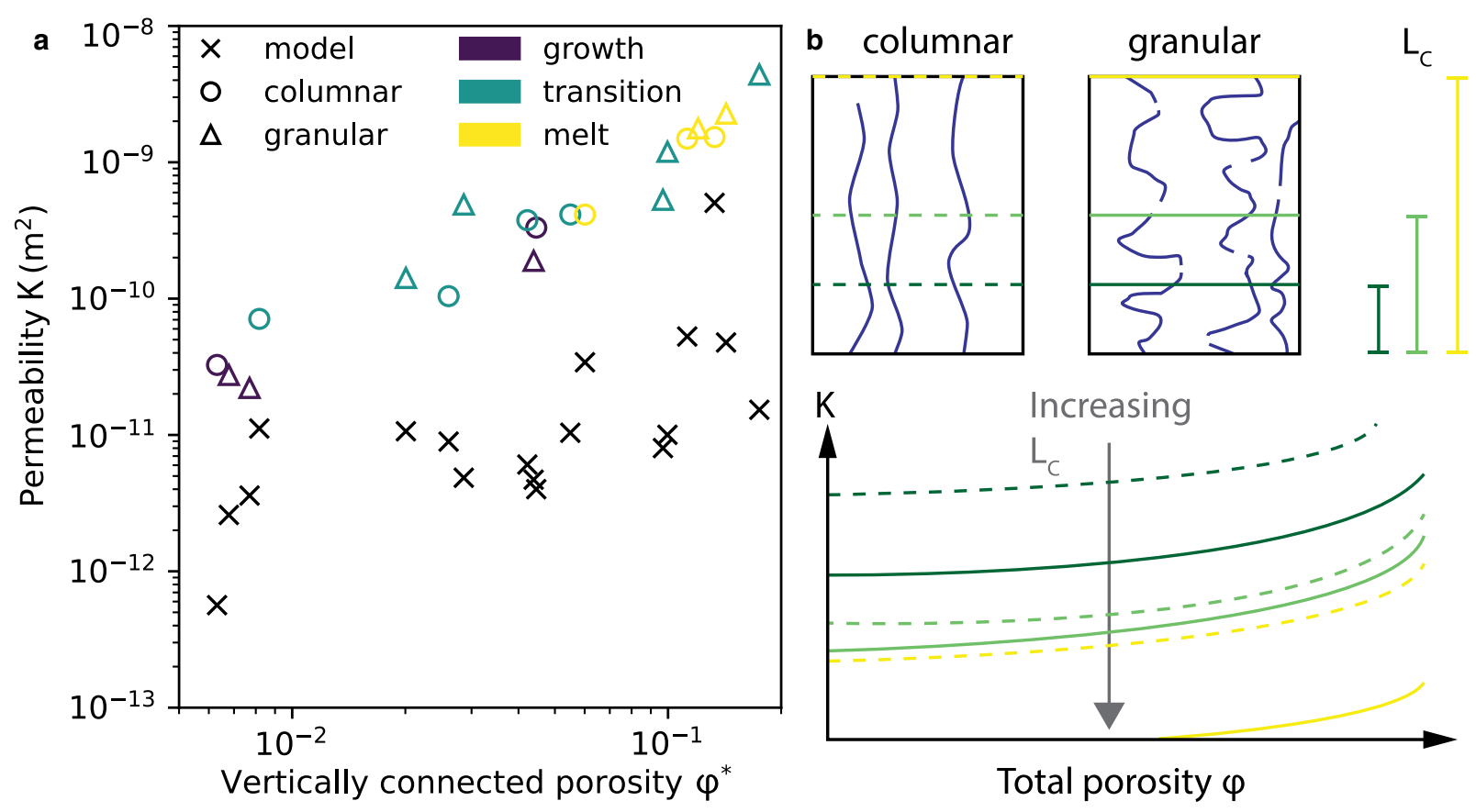

Fig. 10. Relationship between permeability and porosity. (a) Permeability derived from the K-C relationship based on microstructural data collected in this study with a vertical length under consideration of $L_{\mathrm{c}}=0.8 \mathrm{~mm}$ and Kozeny's factor $F \mathrm{~s}=2$. The crosses $(\mathrm{x})$ indicate the permeability computed according to the hierarchical model by Golden and others (2007) with $k=3 \cdot \varphi^{3} \cdot 10^{-8}$, with the brine volume fraction $\varphi$. (b) Impact of the magnitude of the vertical length under consideration $\left(L_{C}\right)$ on the permeability. An increase of the vertical length under consideration leads to a greater decrease in connectivity in granular ice than in columnar ice, which in turn strongly influences the vertical permeability.

the typically nonisometric pore space of columnar ice. The throat size distribution of Lieblappen and others (2018) is based on the definition of the throat size as the length of the minor axis of each inclusions, without differentiating between throats and pores. In fact, the length of the minor axis of an ellipsoid is similar to the radius of a circle or sphere inscribed in that ellipsoid. Finally, Maus and others (2015) used the same definition for pore size as we did in this study, their throat size distribution was determined using a porosimetry algorithm, which returns the pore size distribution extracted from the volume fraction of the pore space accessible by spheres of decreasing diameter injected at the top and bottom of the sample. Thus, the throat size distribution of Lieblappen and others (2018) and Maus and others (2015) do not describe throats as constrictions in a pore space connecting two larger pores as we define them in this study, but consider any sea-ice inclusion as a throat. Finally, bearing in mind that the metrics used to describe size distributions vary between studies, and that the size distribution is also dependent on the imaging resolution, our pore and throat size distributions and the derived seasonal trends are in line with previous work in terms of ice temperature and seasonal stage constraining pore microstructure (Perovich and Gow, 1996; Eicken and others, 2000; Light and others, 2003; Maus and others, 2013; Lieblappen and others, 2018).

The throat length is highly dependent on the chosen porethroat microstructural model and image processing workflow. We chose not to merge chains of pores, although it could be argued that a pore chain corresponds to a single pore, where the pore length is the sum of the throat lengths and pore diameters and the pore radius is a function of throat and pore radius. In addition, the throat length distribution in columnar ice can be compared to the size distribution of the major axis of brine inclusions measured in vertical sections of columnar ice (Eicken and others, 2000, their Fig. 12). This suggests that isolated inclusions in columnar ice are modeled by a pair of pores, the second most common type of pores, behind ending pores. While the throat length distributions for both columnar and granular ice are similar (Figs 6c, g), the presence of longer chains of pores in columnar ice (Fig. 4b), and higher correlation lengths (Fig. 7b), suggests that columnar ice provides a longer pathway for the brine to move through the sample.

\section{Correlation length}

The correlation length pattern for columnar ice (Fig. 7b) is similar to the findings of Pringle and others (2009) with the correlation length diverging with the porosity greater than $5 \%\left(z_{c, c}>7 \mathrm{~mm}\right)$, thus validating our method. In granular ice, while correlation length does not allow drawing any quantitative conclusion about the percolation threshold, the significantly lower correlation length $\left(z_{c, g}<2 \mathrm{~mm}\right)$ than for columnar ice of similar porosity is a clear indication that the granular pore space is less connected for porosity up to $15 \%$. At higher porosity, further work is required due to the small number of high porosity samples. We observed either a pore space becoming connected $\left(z_{c, \mathrm{~g}}>7 \mathrm{~mm}\right)$, or remaining poorly connected $\left(z_{\mathrm{c}, \mathrm{g}}<2 \mathrm{~mm}\right)$ among our samples. The later appears to be paradoxical with respect to the high porosity value $(\varphi>25 \%)$. Based on these data we were not able to determine a percolation threshold for granular ice, although we hypothesize that it exists between 15 and 25\%. Considering that the fluid permeability is limited by the connectivity of the pore space, the permeability is somewhat proportional to the correlation length. Consequently, the vertical permeability of granular ice should be smaller than that of columnar ice $\left(k_{\mathrm{v}, \mathrm{g}}<k_{\mathrm{v}, \mathrm{c}}\right)$.

However, data for the permeability of granular sea ice are not available. While Freitag (1999) measured the anisotropy of permeability between the vertical and horizontal direction in granular ice, no values were published. For columnar ice, the permeability has been described as a function of total brine volume fraction (Golden and others, 2007); however, no such model exists for granular ice. 
The power-law relationship that links porosity to correlation length (Section 4.2.2) can be inverted to relate correlation lengths of granular and columnar ice samples of different porosity. Specifically, we observed that the correlation length in granular ice with a porosity of up to $15 \%$ is $z_{0, \mathrm{~g}}<2 \mathrm{~mm}$, which corresponds to the correlation length of columnar ice with a porosity of about $3-4 \%$. In addition, our analysis is limited by the sample size which does not capture the heterogeneity of the sea-ice cover on the decimeter scale (Weeks, 2010). For example, while observations attest to the development of $\mathrm{cm}$-wide channels as the porosity increases during the transition stage and into the melt season (Petrich and Eicken, 2017), none of our samples displays such features. Thus, while the vertical permeability in granular ice would be lower by up to one order of magnitude relative to that of columnar ice during the growth season, the permeability in granular ice is likely to increase quickly with surface warming of the ice, with disproportional increases in porosity and pore connectivity in the surface granular ice. Ultimately, permeability measurements of granular ice are required to confirm the functional relationships, drawing on pore connectivity and pore shape, explored here.

\section{Tortuosity}

The tortuosity of columnar ice is as low as expected $\left(1<\tau_{\mathrm{c}}<1.1\right.$, Fig. $8 \mathrm{a}$ ), since the tortuosity of straight features is by definition close to 1 , and the pore space in columnar ice consists mostly of vertically elongated pores (Fig. 2). The larger tortuosity values during the melt season are likely the result of lateral and diagonal pore pathways opening up as a result of warming and incipient brine drainage. Later in the season, the presence of fully developed brine channel networks dominated the decreasing tortuosity of the pore space, also observed qualitatively by Cole and Shapiro (1998). Furthermore, the median tortuosity measured with the increasing length of the volume under consideration remains small $\left(1<\tau_{\mathrm{c}}<1.1\right)$, and the spread is consistently narrow $\left(\Delta \tau_{c} \pm 0.05\right.$, Fig. $\left.8 \mathrm{~b}\right)$. These values are to be expected for an elongated and straight geometry, such as brine channels. Simple calculations show that any noticeable kink in a rather straight path will drastically increase the tortuosity to values of $\tau>1.2$. We currently do not have an explanation for the higher tortuosity values observed during the melt stage for vertical lengths under consideration larger than $4 \mathrm{~mm}$. However, the differences between the growth and transition stage are statistically not significant. Additional samples need to be analyzed to shed light on these deviations. The strong agreements between measurements and expectations, based on the known geometry of brine channels in columnar ice, validate the methodology developed in this study, and lend credence to data obtained for granular ice as well.

In granular ice, the larger tortuosity indicates that fluid moving in the pore space must cover on average a distance $30 \%$ longer than that in columnar ice to move over the same Euclidian distance. In extreme cases, this distance in granular ice is double that in columnar ice ( $\tau>2$, Fig. 8$)$. The large variability in small-scale tortuosity in granular ice (Fig. 8a) is of interest. It indicates that the pore space of granular ice is more complex than that of columnar ice at the pore-scale level. Sections of the pore scape with large tortuosity values $(\tau>1.5)$ indicative of convoluted pore geometry, may significantly impede fluid flow through the pore space.

The visible decrease in tortuosity with the advance in the seasonal cycle is linked to the shift in the pore size distribution toward larger values. Protuberances, constrictions, and corners in the pore space increase its tortuosity. With a larger surface-to-volume ratio than a straight tube, these features will see a greater reduction in tortuosity during ice warming and melt than less convoluted pores. Specifically, both pores and throats widen during warming, but constrictions within throats also disappear, reducing tortuosity.

As the vertical length under consideration increases, the likelihood that a connected pathway contains at least a section of pore space with higher tortuosity increases. The presence of a short but very convoluted section is sufficient to increase the overall tortuosity. In addition, a sample where the vertical length under consideration corresponds to the correlation length is likely to contain pore space sections representative of the small-scale tortuosity distribution. This explains the plateau reached in the vertical tortuosity beyond $L_{\mathrm{E}}=4 \mathrm{~mm}$. This characteristic length relates to the size of the representative elementary volume (REV), defined as the scale at which a metric should be measured to avoid pore-scale heterogeneity (Costanza-Robinson and others, 2011).

The median values have mostly converged at $L_{\tau, \mathrm{c}}=7 \mathrm{~mm}$ for columnar ice, and $L_{\tau, \mathrm{g}}=4 \mathrm{~mm}$ for granular ice. The finding for columnar ice is in line with previous observations indicating that columnar ice with a brine volume fraction above $5 \%$ can be considered permeable (Golden and others, 2007), and whose correlation length at such a percolation threshold of $5 \%$ is about $7 \mathrm{~mm}$ (Pringle and others, 2009). However, for columnar ice samples at lower porosities and for granular ice samples with a porosity below $15 \%$, the derived correlation length (Fig. 7b) is smaller than the estimated characteristic length (Fig. 8b). In addition, the variability in tortuosity increases with increasing length under consideration, as shown by the quartile envelope in Fig. 8b. This suggests that measurements of tortuosity that assume a fixed REV conflate the pore-scale tortuosity and the larger-scale connectivity of the pore space. This potential concern can be addressed by either focusing exclusively on the statistics of pore-scale tortuosity (illustrated by the plot in Fig. $8 \mathrm{a}$ ), or for the derivation of bulk properties employ a variable REV that is a function of the observed correlation length.

We resort to the Kozeny-Carman (K-C) relationship to estimate how the broad range of measured tortuosities for granular and columnar ice impacts the vertical permeability. Applied with success to a range of different materials, especially porous rocks (Bear, 1972; Paterson, 1983; Berg, 2014; Schön, 2015), the $\mathrm{K}-\mathrm{C}$ relationship describes permeability as a function of different microstructural parameters. One of its expressions is of particular interest, as the permeability, $k$, depends on the tortuosity $\tau$ and the connected porosity $\varphi^{*}$ :

$$
k=\frac{1}{F_{S} \tau^{2}} \varphi^{*} \frac{1}{S S A^{2}}
$$

where $F_{s}$ is Kozeny's shape factor to account for differently shaped tubes, varying from 2 to 3 for an ellipse-shaped cross-section, and SSA is the SSA of the connected porosity, which can be calculated from 3-D microstructural imaging data.

Figure 10 shows permeabilities derived from the KozenyCarman relationship, which are about two orders of magnitude higher than permeabilities computed from the semi-empirical equation derived from a hierarchical model developed by Golden and others (2007). In addition, in columnar ice, the K-C permeability values overestimate measured permeabilities by a similar factor (Freitag, 1999; Pringle and others, 2009). The discrepancy between Kozeny-Carman and the hierarchical model was to be expected, as the sample volumes over which we measured tortuosity were small, on the order of a few millimeters (Fig. 8b), and each sample had to also be vertically connected with at least one pathway with a diameter of $40 \mu \mathrm{m}-$ corresponding to the minimal resolution of our X-ray measurement - to avoid a zero connected porosity in Eqn (6). The height 
of samples used to measure permeability ranges typically from $5 \mathrm{~cm}$ (Merkel, 2008) up to $20 \mathrm{~cm}$ (Freitag, 1999). This height is several times longer than their correlation length, and thus the open and vertically connected porosity are likely to be smaller. However, since this finding applies to both columnar and granular ice, the ratio of the permeability derived from KozenyCarman for columnar and granular ice still yields valid insights about microstructural controls of permeability.

Bearing in mind the link between tortuosity and pore-space connectivity, and the importance of sampling an REV to avoid the effects of pore-scale heterogeneity for porosity and SSA, we approximated the vertical permeability for both small-scale $\left(L_{\mathrm{E}}=0.8 \mathrm{~mm}\right)$ and other characteristic lengths corresponding to the correlation length for the different seasonal stages $\left(L_{\mathrm{E}}=2\right.$ to $L_{\mathrm{E}}=7 \mathrm{~mm}$ ). While we expected the difference in tortuosity between both textures, apparent for each characteristic length, to drive significant differences in permeability in relation to porosity and SSA, the results were mostly inconclusive.

First, the variability in porosity and SSA decreases with a larger characteristic length $\left(L_{\mathrm{E}}>4 \mathrm{~mm}\right)$, while the variability in tortuosity increases. The opposite trend for the magnitude of variability as a function of the length under consideration contributes to overall consistently large variability in the resulting permeability. Further analysis is required to determine if various characteristic lengths are required to describe different sea-ice microstructural parameters. Second, with respect to the seasonal stage, the high variability in porosity (Fig. 5) and SSA (Fig. 9) results in similar permeability values and ranges for both ice textures. This latter effect is particularly marked during the period between $n$ sea-ice growth and decay, a critical time for biogeochemical processes (Thomas, 2017). The small number of samples collected does not allow us to follow the evolution of microstructure during the transition stage in detail. Additional samples, and replicates, would also benefit the analysis by limiting the impact of potentially unrepresentative samples, such as GT-2 or GM- $0^{*}$.

The transition between an effectively impermeable and a largely permeable sea-ice cover is central to the seasonal evolution of sea ice (Eicken and others, 2002; Pringle and others, 2009; Gradinger and others, 2010). The impact of microstructural changes on ice permeability during the transition between growth and melt season is poorly studied but the key to developing models of fluid transport through sea ice. Here, we discuss this interdependence of microstructure and permeability by focusing on the trends of the variables represented in Eqn (7). At the end of the growth season, the SSA is similar in both columnar and granular ice (Fig. 9). Thus, only the connected porosity and the tortuosity determine permeability contrasts between the two ice types at this stage. The connected porosity is a fraction of the brine volume fraction, which in turn is a function of the sea-ice bulk salinity and temperature (Cox and Weeks, 1983). For an order-of-magnitude estimate of permeability contrasts, we consider granular ice to be confined to the top ice layers and columnar ice to constitute the bulk of the underlying ice cover. For typical salinity profiles at the end of the growth season (Oggier and others, 2020a), salinities of granular and columnar ice are at roughly 10 and $5 \%$, respectively. With a surface temperature of $-10^{\circ} \mathrm{C}$, the brine volume fraction is about $5 \%$ for both ice textures. However, our microstructural data indicate that the pore space of granular ice at such temperatures is less connected than that of columnar ice and thus has a smaller fraction of connected porosity (Figs 2 and 5). Following the requirement of a nonzero value of the connected porosity to obtain a nontrivial value when computing the $\mathrm{K}-\mathrm{C}$ permeability, the sample volume under consideration is only a few millimeters in height, much smaller than samples sectioned for bulk salinity or permeability measurements. Figure $10 \mathrm{~b}$ shows that taller volumes, especially in the case of some of the granular ice samples, lead to a decrease in connected porosity. For some of our samples, the connected porosity reached the critical value of 0 (Fig. 2). Consequently, the $\mathrm{K}-\mathrm{C}$ permeability for granular ice would always be smaller than for columnar ice for a similar total porosity, especially for larger, representative sample sizes of a few centimeters in thickness. With the measured tortuosity values $\left(\tau_{c}=1.1\right.$ and $\left.\tau_{\mathrm{g}}=1.3\right)$ and $20 \%$ less connected porosity in the columnar ice (Fig. 5), granular ice would be at least half as permeable as columnar ice.

With the onset of melt, the upper ice layers warm and granular ice can quickly become much more permeable than columnar ice, as not only the connected porosity in granular ice becomes larger than in columnar ice, but the larger tortuosity of granular ice is counterbalanced by the decrease in its SSA.

Finally, the granular ice structure looks somewhat similar to the highly branched pore space that developed in columnar ice in the presence of extracellular polymeric substances (Krembs and others, 2000; Petrich and Eicken, 2017). While the permeability was not measured directly, Krembs and others (2011) conclude that the increase of spatial complexity of the pore space - as determined from the brine inclusion perimeter to length ratio - should lead to a decrease in permeability. This measure of pore complexity is tied to tortuosity, as a larger perimeter can only be achieved in the presence of pore protuberances that would increase the tortuosity.

\section{Broader implications for fluid transport in sea ice}

Ice texture constraints on tortuosity and connectivity impact fluid flow through sea ice. Put simply, an increase in tortuosity will lengthen the pathway followed by any fluid, and a decrease in connectivity will lower the number of connected pathways throughout a sample. Consequently, the pore space of granular ice with higher tortuosity and lower connectivity is more constricting to fluid flow than the less tortuous, more connected pore space of columnar ice.

Arctic sea ice typically consists of an upper layer of granular ice, usually one to a few decimeters thick, and originating from the early growth stages of sea ice under more dynamic conditions (Weeks, 2010; Petrich and Eicken, 2017). This surface layer is typically underlain by columnar ice grown through the congelation of seawater at the ice bottom. With typical annual Arctic sea-ice growth of 1.0 to $1.8 \mathrm{~m}$, the impact of the tortuous pore space in the granular ice layers remains small considering the total thickness of the columnar ice. However, the lengthening of the openwater season (Markus and others, 2009; Barnhart and others, 2015) with greater fetch and more dynamic freeze-up conditions may contribute to an increase in the thickness and occurrence of granular ice at the expense of columnar ice which requires quiescent growth conditions. Consequently, the ratio of granular to columnar ice is likely to increase in the near future, with the more tortuous pore space of granular ice becoming of greater importance in constraining transport properties of sea ice

In the following, we focus on oil-in-ice transport, specifically the movement of the oil phase through the pore space, which constrains the macroscopic pervasion of oil in ice. Experiments show that if crude oil is spilled under the ice cover during the growth season, it quickly rises toward the surface and that the presence of granular ice strongly hinders oil movement (Oggier and others, 2020b). The microstructural pore data collected in this study can help explain this observation. In columnar ice, oil movement is limited to vertical channels (Oggier and others, 2020b). The pressure differential, driven by the buoyancy difference between oil and sea water, is enough to drive the oil upwards with respect to the channel cross-section (NORCOR, 1975; Maus and others, 2015; Oggier and others, 2020b). The low tortuosity values of 
columnar ice $\left(\tau_{c}<1.1\right)$ do not affect the flow of oil. However, the lower connectivity of the pore space $\left(L_{\mathrm{c}}<2 \mathrm{~mm}\right)$ not only restrains the ability of the oil to move, but also prevents the displaced brine from moving further. In columnar ice during the growth season, the flow is controlled by the vertical sea-ice permeability, previously used by Petrich and others (2013) to estimate oil penetration depth.

As the oil reaches the granular/columnar interface, further oil movement in the columnar ice depends on how easily the oil, and displaced brine, can move through granular ice. The higher tortuosity of granular pore space implies that both oil and brine displaced by invading oil have to move over a longer distance to cover the same vertical displacement. According to the HagenPoiseuille relationship for flow in a tube,

$$
Q=-\frac{\pi R^{4}}{8 \mu} \frac{\Delta p}{\Delta L}
$$

where $R$ is the pore radius and $\mu$ is the dynamic viscosity. If the distance $\Delta L$ increases, the flow $Q$ has to decrease, since the pressure differential, $\Delta p$, in the system is constant. In addition, we need to acknowledge that with oil density close to ice density, expelling oil onto the ice surface requires a pressure differential that is typically larger than that provided by the buoyancy of oil under the ice. This means that once oil and brine have reached hydrostatic equilibrium, additional oil can flow through columnar ice only if oil and displaced brine can spread laterally. Above, we showed that the lateral permeability of columnar ice is lower or equal to that of granular ice. Hence, the oil can and is likely to move laterally after reaching a granular ice layer at the surface. This is consistent with observations made at in large-scale ice tank experiments (Oggier and others, 2020b). Finally, assuming physical properties to be fairly isotropic in granular ice due to its microstructure, the tortuous pore space of granular ice likely controls the oil flow. Further analysis is required to determine connectivity and tortuosity constraints along a pathway that transitions from the vertical migration to lateral spreading.

The movement of oil and displaced brine in both columnar and granular ice pore space is confined to the connected pore space. While the tortuosity of granular ice pores plays a major role, the variability in pore and throat diameter also has a direct effect on oil flow, as the buoyancy-induced pressure differential has to overcome the capillary pressure determined by the pore radius. An increase of tortuosity from 1.1 to 1.5 leads to an increase of the distance $\Delta \mathrm{L}$ by $36 \%$. To maintain a constant flow, $Q$, in Eqn (7), the pressure differential $\Delta p$ has to increase by the same factor. The pressure differential is proportional to the oil lens thickness, $h_{o}$ :

$$
\Delta p=\Delta \rho g h_{o}
$$

Since the density difference between oil and seawater, $\Delta \rho$, is constant, the lens thickness has to increase by $36 \%$ in order for the pressure to increase. At the same time, the capillary pressure, $p_{c}$, in a pore is related to the pressure differential via the YoungLaplace equation (Maus and others, 2015):

$$
\Delta p=p_{c}=\frac{\gamma \cos (\theta)}{R}
$$

Where $R$ is the radius of the pore the oil may invade, $\gamma$ the surface tension between oil and ice, $\theta$ the contact angle of the oil/ice/sea water system. Since the pore radius is inversely proportional to the pressure difference, the required pressure increases by $36 \%$ is similar to a decrease in the pore radius b $25 \%$. Since such a distinction is not clearly visible between pore and throat size distributions (Fig. 6), we conclude that the impact of tortuosity on oil movement should be taken in account when developing pore-scale oil movement models.

In sea-ice modelling, bulk permeability in sea ice is often described by relationships developed by Freitag (1999) and Golden and others (2007). However, both expressions were derived from columnar ice measurements. In the context of a potentially increasing granular-to-columnar-ice ratio due to longer open water seasons and more dynamic ice growth processes in the Arctic, the tortuosity of granular ice pore space may play a more important role in brine and meltwater transport. This is especially true for warming events during the winter and for the transition season, when the combination of lower salinity and temperature creates an impermeable layer within the ice cover, but may allow for large scale lateral movement in the surface ice layers.

A detailed analysis of the stick-and-node model used to determine the pore and throat size distribution, as well as the correlation length, is beyond the scope of this paper. Nonetheless, it is important to point out that a more tortuous pore space increases the probability of encountering a constriction limiting the fluid flow, while covering the same vertical or horizontal distance. A comprehensive analysis of the pore-to-throat ratio would likely improve the K-C permeability approach (Müller-Huber and Schön, 2013), and a statistical description of the extracted 3D pore networks to determine the probability of a pathway to merge, split, or remain may be a necessary step to fully capture the constraints granular pore space imposes on transport processes in sea ice.

\section{Summary and conclusions}

We have presented X-ray CT imaging data showing the seasonal evolution of the sea-ice pore microstructure for both granular and columnar ice. Pore space was imaged at a resolution $(40 \mu \mathrm{m})$ relevant for both oil-in-ice transport and for biogeochemical processes (Krembs and others, 2011). While the 3D reconstructions of the pore space (Fig. 2) display the same contrasts between granular and columnar ice that have previously been highlighted by Weissenberger and others (1992), we quantify these differences through metrics that describe the shape, size and connectivity of the pore space for the ice growth, transition and melt stage.

We found that, overall, the pore and throat size distributions are not significantly different between granular and columnar ice, with the exception of the presence of large spheroidal pores in granular ice, attributed to the presence of air bubbles. However, the vertical pore tortuosity of granular ice $\left(1.2<\tau_{\mathrm{g}}<1.7\right)$ was determined to be significantly larger than that of columnar ice $\left(1.0<\tau_{c}<1.1\right)$, which translates into connected pathways that need to be at least $20 \%$ longer to cover the same vertical distance. In addition, we found that the pore-space correlation length in granular ice is significantly smaller than in columnar ice, and the percolation threshold is higher, both expressions of the fact that the pore space of granular ice is less connected than that of columnar ice.

The combination of these two factors indicates a lower permeability for granular as compared to columnar ice. Drawing on the link between permeability and correlation length, and interpreting microstructural data through the lens of the Kozeny-Carman relationship, we established that the vertical permeability of granular ice is likely to be one order of magnitude smaller during the growth stage than that of columnar ice for the same brine volume fraction. Note for the same brine volume fraction, we established that the connected porosity is smaller in granular ice than in columnar ice. Macroscopic brine or oil movement models 
based on bulk permeability would benefit from a better description of the permeability in relation to pore microstructure (in particular tortuosity and correlation length), for granular and columnar ice as well as other ice textures (platelet ice, mixed granular/columnar, etc.). Such work could prepare the ground for more refined oil-in-ice models and may also improve the representation of the impact of ice texture and ice stratigraphy on heat and brine transport through sea ice.

By showing how the presence of the tortuous granular pore space hinders the vertical movement of oil-in-ice during the growth and transition stages, we highlight the potential importance of this surface layer for other biogeochemical processes or meltwater drainage, whose dependence on ice texture is not well understood. The anticipated increase in the proportion of granular ice in the changing Arctic with more dynamic ice growth conditions lends additional support to the need for such work. Further sampling and data collection are needed, in particular for the transition stage, a critical time in the sea-ice seasonal cycle. Given the limited availability of data, we found no significant difference in the permeability derived from the K-C relationship between granular and columnar ice. Further work is required to quantify the relationship between microstructure and permeability that includes permeability measurements and $3 \mathrm{~d}$ porespace imaging conducted on the same samples.

While bulk pore tortuosity, connectivity, and permeability measurements can contribute to the prediction of macroscopic-scale oil movement, it is also important to understand how the oil and the displaced brine move at a pore microscopic scale level. The idealized pore network extracted with the stick-and-node model includes information required to further identify connected pathways, which are defined in terms of pore-to-throat ratio, tortuosity, and pathway length. Rather than performing computationally expensive fluid dynamic simulations on the full pore space, modeling the flow along such pathways and using bulk properties as boundary conditions may be a promising approach to develop an efficient model that is able to run fast enough to be used in oil spill response settings and large-scale models.

Finally, the more tortuous pore space of granular ice resembles the tortuous pore space of columnar ice in the presence of exopolymer substances observed by Krembs and other (2011). Such changes near the ice bottom would impact not only oil movement but also nutrient exchange and colonization of sea ice by microorganisms. With higher brine viscosities due to exopolymer presence (Krembs and others, 2011), our analysis of pore pathway tortuosity and connectivity is hence also relevant in the context of understanding nutrient, gas, and microbial transport through the lower ice layers. Moreover, this work complements network modeling studies such as that of Steffen and others (2018), that require data describing pore complexity and specifically pore throat sizes and distributions to quantify their role in constricting fluid flow through the ice.

Supplementary material. The supplementary material for this article can be found at https://doi.org/10.1017/jog.2022.1

Acknowledgements. The authors acknowledge the National Science Foundation for funding support through the CMG Program (OPP-0934683), supplemented by the support of the SIZONet Project (OPP-0856867) for work in Utqiagive, as well as a MOSAiC grant (OPP-1735862). We would like to thank Megan O'Sadnick, Josh Jones, Andy Mahoney for contributing to sampling and data collection. Lea Hartl improved the readability of this paper, her help is much appreciated.

Author contributions. Marc Oggier collected data, performed the analysis, and wrote most of the paper. Hajo Eicken collected data and contributed to writing the paper.

Conflict of interest. The authors declare that they have no conflict of interest.
Data. Data used in this manuscript were produced as part of the Seasonal Ice Zone Observing Network (SIZONet). All data are available at the Arctic Data Center (www.arcticdata.io): raw and reconstructed tomography (Oggier and others, 2021), mass balance data (Eicken, 2016), ice core measurement data (Kaufmann, 2016).

\section{References}

Ackley SF and Sullivan CW (1994) Physical controls on the development and characteristics of Antarctic sea ice biological communities- a review and synthesis. Deep-Sea Research Part I 41(10), 1583-1604. doi: 10.1016/ 0967-0637(94)90062-0

Ahrens J, Geveci B and Law C (2005) ParaView: An End-User Tool for LargeData Visualization. In Hansen CD and Johnson CR (eds.) Visualization Handbook. Burlington, MA: Elsevier. doi: 10.1016/B978-012387582-2/ 50038-1.

Arctic Council (2013) Agreement on Cooperation on Marine Oil Pollution Preparedness and Response in the Arctic, 275. Available at http://hdl.handle.net/11374/529.

Arrigo KR (2014) Sea ice ecosystems. Annual Review of Marine Science 6(1), 439-467. doi: 10.1146/annurev-marine-010213-135103

Arrigo KR (2017) Sea ice as a habitat for primary producers. In Thomas DN (ed.) Sea Ice. https://doi.org/10.1002/9781118778371

Banerjee R and 6 others (2019) Carbon felt electrodes for redox flow battery: impact of compression on transport properties. Journal of Energy Storage $\mathbf{2 6}$ (October), 100997. doi: 10.1016/j.est.2019.100997

Barnhart KR, Miller CR, Overeem I and Kay JE (2015) Mapping the future expansion of Arctic open water. Nature Climate Change 6(November), 1-6. doi: $10.1038 /$ nclimate2848

Bear J (1972) Dynamics of Fluids in Porous Media. New York: American Elsevier Publishing.

Berg CF (2014) Permeability description by characteristic length, tortuosity, constriction and porosity. Transport in Porous Media 103(3), 381-400. doi: 10.1007/s11242-014-0307-6

Bluhm BA and Gradinger R (2008) Regional variability in food availability. Ecological Applications 18(2), S77-S96. (http://dx.doi.org/10.1890/06-0562.1

Bock C and Eicken H (2005) A magnetic resonance study of temperaturedependent microstructural evolution and self-diffusion of water in Arctic first-year sea ice. Annals of Glaciology 40, 179-184. doi: 10.3189/ 172756405781813645

Buffo JJ, Schmidt BE and Huber C (2018) Multiphase reactive transport and platelet ice accretion in the sea ice of McMurdo sound, Antarctica. Journal of Geophysical Research: Oceans 123(1), 324-345. doi: 10.1002/2017JC013345

Clennell MB (1997) Tortuosity: a guide through the maze. Geological Society Special Publication 122(122), 299-344. doi: 10.1144/GSL.SP.1997.122.01.18

Cole DM and Shapiro LH (1998) Observations of brine drainage networks and microstructure of first-year sea ice. Journal of Geophysical Research: Oceans 103(C10), 21739-21750. doi: 10.1029/98JC01264

Costanza-Robinson MS, Estabrook BD and Fouhey DF (2011) Representative elementary volume estimation for porosity, moisture saturation, and air-water interfacial areas in unsaturated porous media: data quality implications. Water Resources Research 47(7), 1-12. doi: 10.1029/ 2010WR009655

Cottier F, Eicken H and Wadhams P (1999) Linkages between salinity and brine channel distribution in young sea ice. Water Resources Research 104 (C7), 15859-15871. doi: 10.1029/1999JC900128/

Cox GFN and Weeks WF (1983) Equations for determining the gas and brine volumes in sea-ice samples. Journal of Glaciology 29(102), 306-316. doi: 10. $1017 /$ S0022143000008364

Crabeck $\mathbf{O}$ and 9 others (2016) Imaging air volume fraction in sea ice using non-destructive X-ray tomography. The Cryosphere 10(3), 1125-1145. doi: 10.5194/tc-10-1125-2016

Dong $\mathbf{H}$ and Blunt MJ (2009) Pore-network extraction from micro-computerized-tomography images. Physical Review E 80(3), 036307. doi: 10.1103/PhysRevE.80.036307

Druckenmiller ML, Eicken H, Johnson MA, Pringle DJ and Williams CC (2009) Toward an integrated coastal sea-ice observatory: system components and a case study at Barrow, Alaska. Cold Regions Science and Technology 56(2-3), 61-72. doi: 10.1016/j.coldregions.2008.12.003

Eguíluz VM, Fernández-Gracia J, Irigoien X and Duarte CM (2016) A quantitative assessment of Arctic shipping in 2010-2014. Scientific Reports 6(1), 30682. doi: 10.1038/srep30682 
Eicken H (2016) Automated ice mass balance site (SIZONET). doi: 10.18739/ A2D08X

Eicken H, Bock C, Wittig R, Miller H and Poertner H-O (2000) Magnetic resonance imaging of sea-ice pore fluids: methods and thermal evolution of pore microstructure. Cold Regions Science and Technology 31(3), 207225. doi: 10.1016/S0165-232X(00)00016-1

Eicken H, Krouse HR, Kadko D and Perovich DK (2002) Tracer studies of pathways and rates of meltwater transport through Arctic summer sea ice. Journal of Geophysical Research: Oceans 107(10), 1-20. doi: 10.1029/ 2000jc000583

Feltham DL, Untersteiner N, Wettlaufer JS and Worster MG (2006) Sea ice is a mushy layer. Geophysical Research Letters 33(14), L14501. doi: 10.1029/ 2006GL026290

Frantz CM and 7 others (2019) Physical and optical characteristics of heavily melted 'rotten' Arctic sea ice. The Cryosphere 13, 775-793. doi: 10.5194/ tc-2018-141

Freitag J (1999) The hydraulic properties of Arctic Sea-Ice - Implications for the small scale particle transport. Alfred-Wegener-Institut fur Polar- und Meeresforschung

Freitag J and Eicken H (2003) Meltwater circulation and permeability of Arctic summer sea ice derived from hydrological field experiments. Journal of Glaciology 49(166), 349-358. doi: 10.3189/172756503781830601

Galley RJ and 6 others (2015) Imaged brine inclusions in young sea iceshape, distribution and formation timing. Cold Regions Science and Technology 111, 39-48. doi: 10.1016/j.coldregions.2014.12.011

Golden KM and 5 others (2007) Thermal evolution of permeability and microstructure in sea ice. Geophysical Research Letters 34(16), 1-6. doi: 10.1029/2007GL030447

Gommes CJ, Bons A-J, Blacher S, Dunsmuir JH and Tsou AH (2009) Practical methods for measuring the tortuosity of porous materials from binary or gray-tone tomographic reconstructions. American Institute of Chemical Engineers Journal 55(8), 2000-2012. doi: 0.1002/aic.11812.

Gostick J and 11 others (2016) OpenPNM: a pore network modeling package. Computing in Science \& Engineering 18(4), 60-74. doi: 10.1109/MCSE.2016.49

Gostick JT (2017) Versatile and efficient pore network extraction method using marker-based watershed segmentation. Physical Review E 96(2) 023307. doi: 10.1103/PhysRevE.96.023307

Gostick J and 6 others (2019) PoreSpy: a python toolkit for quantitative analysis of porous media images. Journal of Open Source Software 4(37), 1296 doi: $10.21105 /$ joss.01296

Gradinger R and 6 others (2010) Marine life in the Arctic. In McIntyre AD (ed.) Life in the World's Oceans. Oxford, UK: Wiley-Blackwell, pp. 183202. doi: 10.1002/9781444325508.ch10

Griewank PJ and Notz D (2013) Insights into brine dynamics and sea ice desalination from a 1-D model study of gravity drainage. Journal of Geophysical Research: Oceans 118(7), 3370-3386. doi: 10.1002/jgrc.20247

Horner R and 9 others (1992) Ecology of sea ice biota. Polar Biology 12(3-4), 417-427. doi: 10.1007/BF00243113

Hounsfield GN (1973) Computerized transverse axial scanning (tomography): part 1. Description of system. The British Journal of Radiology 46(552), 1016-1022. doi: 10.1259/0007-1285-46-552-1016

Hudier EJ-J, Ingram RG and Shirasawa K (1995) Upward flushing of sea water through first year ice. Atmosphere-Ocean 33(3), 569-580. doi: 10. 1080/07055900.1995.9649545

Hunter JD (2007) Matplotlib: a 2D graphics environment. Computing in Science and Engineering 9(3), 90-95. doi: 10.1109/MCSE.2007.55

Jervis $\mathbf{R}$ and 8 others (2018) In situ compression and X-ray computed tomography of flow battery electrodes. Journal of Energy Storage 27(5), 13531361. doi: $10.1016 /$ j.jechem.2018.03.022

Jones KA, Ingham M and Eicken H (2012) Modeling the anisotropic brine microstructure in first-year Arctic sea ice. Journal of Geophysical Research: Oceans 117(C2), C02005. doi: 10.1029/2011JC007607

Kaufmann M (2016) Sea-ice core measurements. Arctic Data Center. doi: 10. 18739/A2XP6V39R

Kawamura T (1988) Observations of the internal structure of sea ice by X ray computed tomography. Journal of Geophysical Research 93(C3), 2343. doi 10.1029/JC093iC03p02343

Kawamura T, Ishikawa M, Takatsuka T, Kojima S and Shirasawa K (2006) Measurements of Permeability of Sea Ice. Proceedings of the 18th IAHR International Symposium on Ice (January 2006), 105-112.

Krembs C, Eicken H and Deming JW (2011) Exopolymer alteration of physical properties of sea ice and implications for ice habitability and biogeochemistry in a warmer Arctic. Proceedings of the National Academy of Sciences 108(9), 3653-3658. doi: 10.1073/pnas.1100701108

Krembs C, Gradinger R and Spindler M (2000) Implications of brine channel geometry and surface area for the interaction of sympagic organisms in Arctic sea ice. Journal of Experimental Marine Biology and Ecology 243 (1), 55-80. doi: 10.1016/S0022-0981(99)00111-2

Lieb-Lappen RM, Golden EJ and Obbard RW (2017) Metrics for interpreting the microstructure of sea ice using X-ray micro-computed tomography. Cold Regions Science and Technology 138, 24-35. doi: 10.1016/j.coldregions.2017.03.001

Lieblappen RM, Kumar DD, Pauls SD and Obbard RW (2018) A network model for characterizing brine channels in sea ice. The Cryosphere 12(3), 1013-1026. doi: 10.5194/tc-12-1013-2018

Light B, Maykut GA and Grenfell TC (2003) Effects of temperature on the microstructure of first-year Arctic sea ice. Journal of Geophysical Research: Oceans 108(C2), 1-16. doi: 10.1029/2001JC000887.

Lubin D and Massom R (2006) Polar Remote Sensing. Volume 1: Atmosphere and Polar Oceans. Chichester, UK; Berlin, Germany: Praxis/Springer. doi: 10.1007/3-540-30785-0.

Markus T, Stroeve JC and Miller J (2009) Recent changes in Arctic sea ice melt onset, freezeup, and melt season length. Journal of Geophysical Research 114(C12), C12024. doi: 10.1029/2009JC005436

Maus S and 5 others (2015) Oil saturation of the sea ice pore space. Proceedings of the 23st International Conference on Port and Ocean Engineering under Arctic Conditions (June), 1-12. Available at http://wxreview.org/temp/POAC15/pdf/poac15Final00244.pdf.

Maus S, Leisinger S, Matzl M, Schneebeli M and Wiegmann A (2013) Modelling oil entrapment in sea ice on the basis of 3d micro-tomographic images. Proceedings of the 22nd International Conference on Port and Ocean Engineering under Arctic Conditions (October 2015), 1-10 Available at http://www.geodict.de/Publications/2013POAC_MausEtAl.pdf.

McKinney W (2010) Data structures for statistical computing in python. Proceedings of the 9th Python in Science Conference 1697900(Scipy), 5156 Available at http://conference.scipy.org/proceedings/scipy2010/mckinney.html.

Meiners KM and Michel C (2017) Dynamics of nutrients, dissolved organic matter and exopolymers in sea ice. In Thomas DN (ed.) Sea Ice, https:// doi.org/10.1002/9781118778371

Merkel H (2008) Impact of ice Permeability and Under-ice Water Currents on Nutrient Dynamics in Arctic sea ice. (University of Alaska Fairbanks, Fairbanks)

Müller-Huber E and Schön J (2013) Carbonates with complex pore systems modeling of permeabilities and application of modified capillary tube models. Society of Exploration Geophysicists International Exposition and 83rd Annual Meeting, SEG 2013: Expanding Geophysical Frontiers, 2587-2591. doi: 10.1190/segam2013-0012.1.

NORCOR (1975) The Interaction of Crude Oil With Arctic Sea Ice. Victoria, BC, Canada: Canadian D.

Oggier M, Eicken H, Jin M and Høyland K (2020a) Seasonal and interannual variability of sea-ice state variables: observations and predictions for landfast ice in northern Alaska and svalbard. The Cryosphere Discussions 2020, 1-28. doi: 10.5194/tc-2020-52.

Oggier M, Eicken H and O'Sadnick M (2021) Sea-ice tomography data set, Utqiagvik, Alaska, 2013-2014. Arctic Data Center. doi: 10.18739/A2F47GV5N

Oggier M, Eicken H, Wilkinson JP, Petrich C and O'Sadnick M (2020b) Crude oil migration in sea-ice: laboratory studies of constraints on oil mobilization and seasonal evolution. Cold Regions Science and Technology 174(October 2019), 102924. doi: 10.1016/j.coldregions.2019.102924

O'Sadnick M (2015) In-Situ Monitoring of Sea Ice Dielectric Properties and Implications for the Tracking of Seasonal Evolution of Microstructure. Fairbanks: University of Alaska. Available at https://scholarworks.alaska. edu/handle/11122/6117.

O'Sadnick M, Ingham M, Eicken H and Pettit E (2016) In situ field measurements of the temporal evolution of low-frequency sea-ice dielectric properties in relation to temperature, salinity, and microstructure. The Cryosphere 10(6), 2923-2940. doi: 10.5194/tc-10-2923-2016

Paterson MS (1983) The equivalent channel model for permeability and resistivity in fluid-saturated rock-a re-appraisal. Mechanics of Materials 2(4), 345-352. doi: 10.1016/0167-6636(83)90025-X

Perovich DK and Gow AJ (1991) A statistical description of the microstructure of young sea ice. Journal of Geophysical Research 96(C9), 16943. doi: $10.1029 / 91 j \mathrm{jc} 01594$ 
Perovich DK and Gow AJ (1996) A quantitative description of sea ice inclusions. Journal of Geophysical Research: Oceans 101(C8), 18327-18343. doi: 10.1029/96JC01688

Petrich C and Eicken H (2017) Overview of sea ice growth and properties. In Thomas DN (ed.) Sea Ice. https://doi.org/10.1002/9781118778371

Petrich C, Karlsson J and Eicken H (2013) Porosity of growing sea ice and potential for oil entrainment. Cold Regions Science and Technology, 87, 27-32. doi: 10.1016/j.coldregions.2012.12.002

Petrich C, Langhorne PJ and Sun ZF (2006) Modelling the interrelationships between permeability, effective porosity and total porosity in sea ice. Cold Regions Science and Technology 44(2), 131-144. doi: 10.1016/j.coldregions.2005.10.001

Pringle DJ, Miner JE, Eicken H and Golden KM (2009) Pore space percolation in sea ice single crystals. Journal of Geophysical Research 114(C12), C12017. doi: 10.1029/2008JC005145

Rabbani A, Jamshidi S and Salehi S (2014) An automated simple algorithm for realistic pore network extraction from micro-tomography images. Journal of Petroleum Science and Engineering 123, 164-171. doi: 10.1016/ j.petrol.2014.08.020

Schön JH (2015) Pore space properties. Developments in Petroleum Science 65, 21-84. doi: 10.1016/B978-0-08-100404-3.00002-0.

Silin D and Patzek T (2006) Pore space morphology analysis using maximal inscribed spheres. Physica A: Statistical Mechanics and its Applications 371 (2), 336-360. doi: 10.1016/j.physa.2006.04.048

Steffen KR and 5 others (2018) Network modeling of fluid transport through sea ice with entrained exopolymeric substances. Multiscale Modeling \& Simulation 16(1), 106-124. doi: 10.1137/17M1117513

Steiner $\mathbf{N}$ and 9 others (2016) What sea-ice biogeochemical modellers need from observers. Elementa: Science of the Anthropocene 4, 000084. doi: 10. 12952/journal.elementa.000084

Taillon JA, Pellegrinelli C, Huang YL, Wachsman ED and Salamanca-Riba LG (2018) Improving microstructural quantification in FIB/SEM nanotomography. Ultramicroscopy 184, 24-38. doi: 10. 1016/j.ultramic.2017.07.017
Thomas DN (2017) Sea ice, 3rd Ed. Chichester, UK; Hoboken, NJ: John Wiley \& Sons. http://eu.wiley.com/WileyCDA/WileyTitle/productCd-1118778383. html.

Vancoppenolle M and 11 others (2013) Role of sea ice in global biogeochemical cycles: emerging views and challenges. Quaternary Science Reviews 79 207-230. doi: 10.1016/j.quascirev.2013.04.011

Vancoppenolle M, Bitz CM and Fichefet T (2007) Summer landfast sea ice desalination at point Barrow, Alaska: modeling and observations. Journal of Geophysical Research 112(C4), C04022. doi: 10.1029/ 2006JC003493

van der Walt S, Colbert SC and Varoquaux G (2011) The NumPy array: a structure for efficient numerical computation. Computing in Science and Engineering 13(2), 22-30. doi: 10.1109/MCSE.2011.37

Van Rossum G and Drake FL (2009) Python 3 Reference Manual. Scotts Valley, CA: CreateSpace.

Virtanen $\mathbf{P}$ and 33 others (2020) SciPy 1.0: fundamental algorithms for scientific computing in Python. Nature Methods 17(3), 261-272. doi: 10.1038/ s41592-019-0686-2

Webster $\mathbf{M}$ and 8 others (2018) Snow in the changing sea-ice systems. Nature Climate Change 8(11), 946-953. doi: 10.1038/s41558-018-0286-7

Weeks WF (1998) Growth conditions and structure and properties of sea ice. In Leppäranta $\mathrm{M}$ ed. Physics of Ice-Covered Seas. Helsinki: Helsinki University Press, Vol.1, pp. 25-104.

Weeks WF (2010) On Sea Ice. Fairbanks, AK: University.

Weissenberger J, Dieckmann G, Gradinger R and Spindler M (1992) Sea ice: a cast technique to examine and analyze brine pockets and channel structure. Limnology and Oceanography 37(1), 179-183. doi: 10.4319/lo.1992. 37.1.0179

Wells AJ, Wettlaufer JS and Orszag SA (2011) Brine fluxes from growing sea ice. Geophysical Research Letters 38(November 2010), 1-5. doi: 10.1029/ 2010GL046288

Wilkinson JP and 7 others (2015) Detection and quantification of oil under sea ice: the view from below. Cold Regions Science and Technology 109, 9-17. doi: 10.1016/j.coldregions.2014.08.004 